Estudios Geológicos, 66(2)

julio-diciembre 2010, 147-156

ISSN: 0367-0449

doi:10.3989/egeol.40051.083

\title{
Petrología y geoquímica del granito Los Cuartos, Tafí del Valle, Tucumán, noroeste de Argentina: integración al esquema magmático regional
}

\author{
Petrology and geochemistry of the Los Cuartos granite, \\ Tafí del Valle, Tucuman, northwest of Argentina: \\ its integration to the regional magmatic layout
}

\author{
J.P. López ${ }^{1}$, L.I. Bellos ${ }^{1}$
}

RESUMEN

El Granito Los Cuartos aflora sobre la ladera occidental de Cumbres Calchaquíes, al E de la localidad de Tafí del Valle, provincia de Tucumán, Argentina. Es de composición granítica a granodiorítica, con desarrollo de dos micas, predominando la biotita. Es de grano medio e inequigranular, con megacristales de feldespato potásico raros o ausentes. Contiene xenolitos de la roca de caja con diferentes grados de digestión. Este cuerpo desarrolla fenómenos de metamorfismo de contacto en el basamento al que intruye, con desarrollo de porfiroblastos de andalucita y biotita poiquiloblástica. El granitoide presenta características calcoalcalina, peraluminosos, rico en $\mathrm{K}$ y $\mathrm{P}$ y con contenidos comparativamente más bajos en $\mathrm{Ca}$ y $\mathrm{Na}$ que los granitoides del área; poseen rasgos tardío-tectónicos con respecto a la deformación y su emplazamiento se habría producido durante el Ordovícico (Ciclo Famatiniano).

Palabras clave: Granito Los Cuartos, Megafractura de Tafí, Cumbres Calchaquíes, Ciclo Famatiniano.

\begin{abstract}
Los Cuartos Granite crops out on the western flank of the Cumbres Calchaquíes, east of Tafí del Valle, Tucumán Province, Argentina. It has a granitic to granodioritic composition, of two micas, being biotite dominant. The granite is medium grained and inequigranular, with rare K-feldspar megacrysts. It contains host-rock xenoliths with different degrees of assimilation. The granite intrusion produced contact metamorphism in the surrounding basement, with development of andalucite porphyroblasts and poikiloblastic biotite. The granite is calk-alkaline and peraluminous, and is $\mathrm{K}$ - and $\mathrm{P}$-rich and $\mathrm{Ca}$ - and $\mathrm{Na}$ poor compared to other granitoids of the region. The pluton shows late-tectonic features with regard to the regional deformation. The granite possibly intruded during the Ordovician (Famatinian Cycle) and its emplacement was structurally controlled by the Tafí Megafracture. Los Cuartos Granite and other intrusive bodies of the region share similar petrographical, geochemical, structural and geochronological characteristics.
\end{abstract}

Keywords: Los Cuartos Granite, Tafí Megastructure, Cumbres Calchaquíes, Famatinian Cycle.

\section{Introducción}

La Megafractura de Tafí (Baldis et al., 1975) es una estructura que divide las Sierras del Aconquija de Cumbres Calchaquíes, con rumbo general NNO-SSE y con desplazamiento vertical normal inclinando al SO y componente horizontal dextral (Gutiérrez \&
Mon, 2004). A lo largo de esta fractura se emplazaron numerosos cuerpos graníticos en un basamento metamórfico de bajo y mediano grado. Las características petrológicas y geoquímicas, sus niveles de emplazamiento y la génesis de muchos de estos cuerpos fueron objeto de estudios realizados anteriormente (Saavedra et al., 1984; Toselli et al., 1985)

\footnotetext{
1 INSUGEO-CONICET, Facultad de Ciencias Naturales e IML-UNT. Miguel Lillo, 205. CP 4000. San Miguel de Tucumán, Argentina. Email: lopezjp00@yahoo.com.ar
} 
mientras que otros intrusivos de la zona sólo fueron mencionados someramente como parte de trabajos regionales en los que se describió al basamento de la región y se elaboró un esquema tentativo de los eventos de deformación y metamorfismo (Toselli \& Rossi de Toselli, 1973 y 1984; Toselli, 1992).

La zona estudiada se localiza en las adyacencias de Los Cuartos, sobre la ladera occidental de Cumbres Calchaquíes al E de la localidad de Tafí del Valle, Departamento Tafí, Provincia de Tucumán. Sus coordenadas geográficas son $26^{\circ} 51^{\prime}$ latitud sur y $65^{\circ} 40^{\prime}$ longitud oeste (fig. 1).

En el presente trabajo se realiza un estudio petrográfico y geoquímico detallado y actualizado del faldeo occidental del Granito de Los Cuartos, con el objetivo de integrar este cuerpo plutónico al esquema regional de intrusividad y establecer características distintivas o comunes con otros intrusivos descritos en la zona, relacionadas a su mineralogía, quimismo, condiciones de emplazamiento, relación con la roca de caja y tendencia evolutiva.

\section{Antecedentes}

Las Cumbres Calchaquíes forman parte del Cratógeno Central Calchaquí (Baldis et al., 1975) e integran la faja oriental de las Sierras Pampeanas Noroccidentales (Caminos, 1979).

En la región se reconocen principalmente afloramientos de esquistos bandeados cuarzo-biotíticomuscovítico-cloríticos, con escasa plagioclasa ácida y con desarrollo local de asociaciones con granate y con estaurolita-granate, y rocas intrusivas predominantemente graníticas, desde el Cerro Pabellón hasta más allá de la Ciénaga Amarilla (Toselli \& Rossi de Toselli, 1984).

La región estudiada pertenece a la zona IV de la división tectonometamórfica del basamento del Noroeste Argentino (Willner \& Miller, 1986; Wilner, 1990), que se caracteriza por dos eventos metamórficos, siendo el segundo de mediano grado con crecimiento estático de porfiroblastos de estaurolita, almandino y andalucita. Toselli (1992) incluye al sector estudiado en la Zona III, en su división del basamento metamórfico del Ciclo Pampeano en base a características petrográficas y mineralógicas. Toselli \& Rossi de Toselli (1984) y Toselli (1992) reconocen la presencia de esquistos bandeados en los que se desarrollan dos fases principales de deformación y metamorfismo: la deformación D1, sincinemática con $\mathrm{M} 1$, que da lugar al bandeado característico y a la asociación cuarzo, moscovita, plagioclasa, biotita y granate y una deformación D2, de rango estaurolita, asociada a fenómenos metamórficos acontecidos en el Ciclo Famatiniano (Cámbrico Medio-Devónico Superior) de Aceñolaza \& Toselli (1976).

Toselli \& Rossi de Toselli (1984) hacen referencia sucintamente al plutón aflorante en la localidad de Los Cuartos, en contacto con los esquistos estaurolítico-granatíferos, que clasifican petrográficamente como granito-granodiorita y Toselli (1992) señala los fenómenos de asimilación de la roca de caja que presenta el granito de Mala-Mala en inmediaciones de la quebrada de Los Cuartos.

\section{Magmatismo de Sierras Pampeanas Orientales}

El magmatismo granítico de las Sierras Pampeanas Orientales puede clasificarse, siguiendo criterios cronológicos (Rapela et al., 1990) en:

G1: Granitoides Pampeanos (Proterozocio superior-Cámbrico medio).

G2: Granitoides Famatinianos (Cámbrico superior-Devónico medio).

G3: Granitoides de edad Devónica a Carbonífera.

Los granitoides G2 pueden subdividirse, en base a relaciones temporales con el segundo evento tectonometamórfico reconocido en la región, en granitoides sin-D2, tardío-D2 y post-D2 (Rapela et al., 1992).

Los Granitoides G1 son pequeños cuerpos de tonalitas, dioritas, tonalitas, gabros y hornblenditas que intruyen al complejo metamórfico antes y durante una fase deformacional temprana y metamorfismo regional (D1 y M1, Rapela et al., 1992) como los descritos en la sierra de Ancasti y en la sierra de Aconquija (fuera de la zona de estudio).

Por su parte, los Granitoides G2 constituyen grandes cuerpos y batolitos de amplio espectro composicional, que integran el Cinturón Móvil Famatiniano (Pankhurst et al., 2000). Dentro de este grupo, los Granitoides sin-D2 se caracterizan por ser pequeños cuerpos concordantes, con formas lenticulares y contactos netos (por ejemplo la tonalita Tolombón, en la sierra de Quilmes), de composición tonalítica a granítica, con biotita y biotitamoscovita. Los Granitoides tardío-D2 varían de tamaños desde plutones homogéneos, como el Granito Loma Pelada, a pequeños batolitos polifásicos con zonación asimétrica, como el Granito Cafayate, 


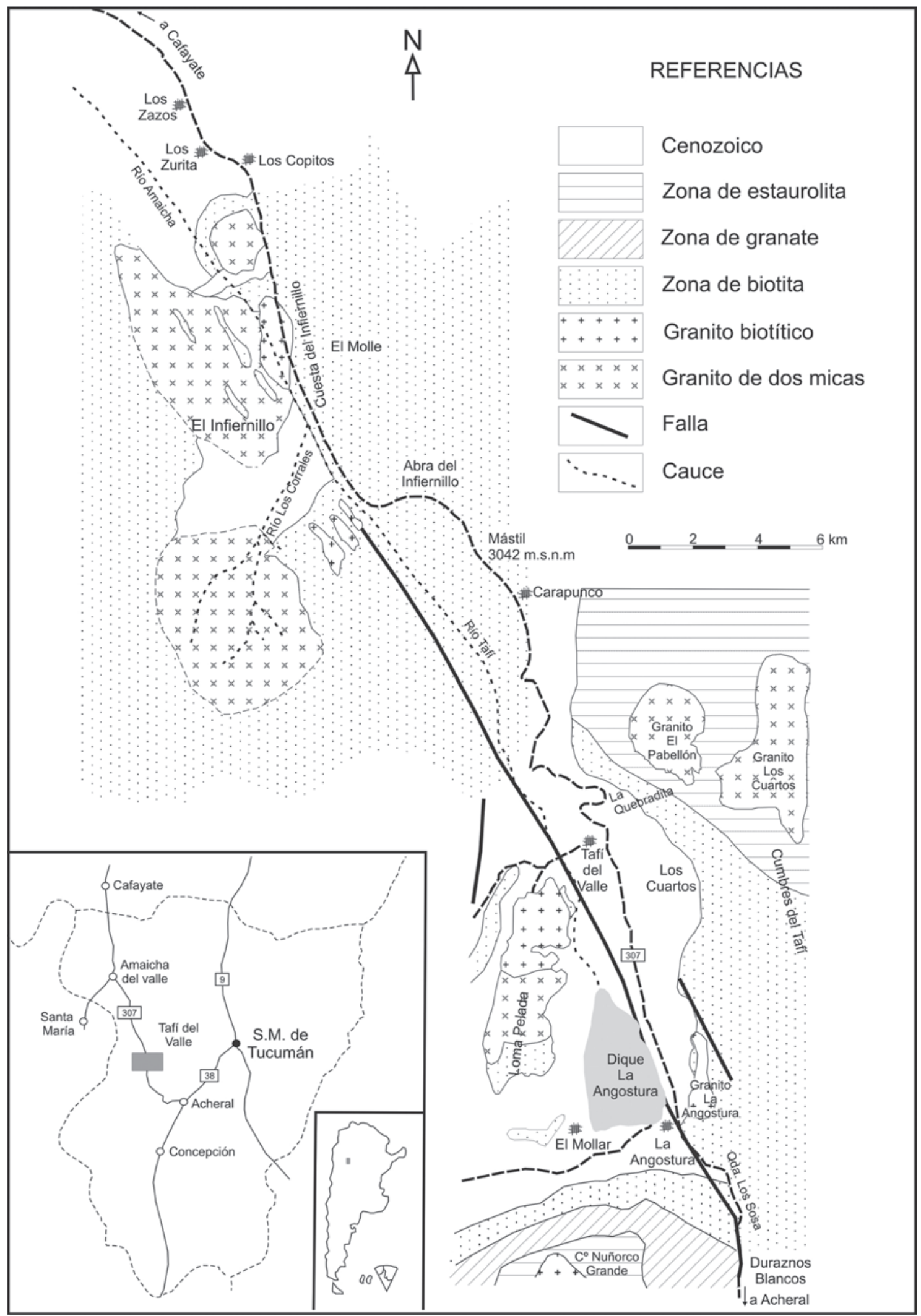

Fig. 1.-Esquema geológico de la zona de estudio. 
emplazado fuera de la zona de estudio, en las inmediaciones de la localidad de Cafayate, Provincia de Salta. Son parcialmente concordantes con la roca de caja y desarrollan aureolas de contacto (Rapela et al., 1992). La característica composicional principal es la peraluminosidad y varían desde tonalitas hasta granitos, predominando las granodioritas. Los Granitoides post-D2 (Batolito de Achala, Provincia de Córdoba) alcanzan tamaño de grandes dimensiones, desarrollan aureolas de contacto y predominan las composiciones graníticas.

Finalmente, los Granitoides G3, como el Granito Cerro Amarillo, emplazado en cercanías de Cafayate, se caracterizan por ser pequeños plutones epizonales de composición granítica a cuarzo-monzonítica con fenocristales de feldespato alcalino, biotita y hornblenda.

\section{Geología del área de estudio}

\section{Rocas metamórficas}

El complejo metamórfico presenta una estructura esquistosa orientada NW-SE con rumbo dominante $45^{\circ} \mathrm{N}$ e inclinaciones que varían entre 60 y $80^{\circ}$ al $\mathrm{E}$ y al W. Está compuesto por esquistos bandeados que presentan una variación mineralógica bien definida, caracterizada por la alternancia de una zona Qtz-BtMs-Chl y de una zona con la asociación Grt-St (Toselli \& Rossi de Toselli, 1984). Intercalados, se reconocen delgados lentes de felsitas calcosilicáticas, resultantes del metamorfismo de sedimentos carbonáticos (Rossi de Toselli et al., 1982 y Toselli \& Rossi de Toselli, 1984).

La zona de biotita, reconocida por Toselli \& Rossi de Toselli (1984), se encuentra en el sector más occidental de la quebrada de La Puerta y presenta las siguientes paragénesis:

$\mathrm{Chl}-\mathrm{Bt}-\mathrm{Qtz}-\mathrm{Ms} \pm \mathrm{Pl}$ ácida.

Chl $-\mathrm{Ms}-\mathrm{Qtz} \pm \mathrm{Pl}$ ácida.

$\mathrm{Bt}-\mathrm{Qtz}-\mathrm{Ms} \pm \mathrm{Pl}$ ácida (abreviaciones minerales de Kretz, 1983).

Por su parte, la zona de la estaurolita, que se reconoce al E de la anterior, hacia el contacto con el cuerpo granítico, está definida por las paragénesis

$$
\begin{aligned}
& \mathrm{St}-\mathrm{Bt}-\mathrm{Chl}-\mathrm{Qtz}-\mathrm{Ms} \pm \mathrm{Pl} \text { ácida. } \\
& \mathrm{St}-\mathrm{Bt}-\mathrm{Grt}-\mathrm{Qtz}-\mathrm{Ms}-\mathrm{Chl} \pm \mathrm{Pl} \text { ácida. }
\end{aligned}
$$

Además de las mencionadas zonas, se ha reconocido dentro del basamento metamórfico una zona con desarrollo de andalucita, en las proximidades del cuerpo intrusivo, junto a desarrollo estático de biotita poiquiloblástica. Las reacciones que habrían dado lugar a la formación de este silicato de aluminio serían las siguientes (Winkler, 1976):

$\mathrm{Chl}$ rica en $\mathrm{Mg}+\mathrm{St}+\mathrm{Ms}+\mathrm{Qtz} \rightarrow \mathrm{And}+\mathrm{Bt}+\mathrm{H}_{2} \mathrm{O}$. $\mathrm{Chl}$ rica en $\mathrm{Mg}+\mathrm{Ms}+\mathrm{Qtz}+\rightarrow \mathrm{And}+\mathrm{Bt}+\mathrm{H}_{2} \mathrm{O}$.

Las lentes calcosilicáticas presentan asociaciones mineralógicas que incluyen actinolita y granate en una masa de grano muy fino de cuarzo y plagioclasa.

\section{Granito Los Cuartos}

El granito los Cuartos constituye un cuerpo elongado de rumbo submeridional con ejes de $2 \times 7 \mathrm{~km}$, que se aloja en el basamento metamórfico en el que ocasiona metamorfismo térmico, con desarrollo de andalucita y biotita poiquiloblástica.

Petrográficamente corresponde a monzogranitos y granodioritas (fig. 2) de dos micas, con predominancia de biotita. Es un cuerpo de coloración gris a gris rosado, de grano medio e inequigranular, megacristales de feldespato potásico son raros o están ausentes. Contiene numerosos xenolitos de la roca de caja de tamaños que varían desde centímetros hasta metros, con diferentes grados de digestión, algunos presentan contactos netos y un delgado borde biotítico mientras que otros presentan bordes difusos con importantes fenómenos de asimilación.

Microscópicamente es posible reconocer su textura inequigranular xenomórfica a hipidiomórfica, donde la plagioclasa es en general el feldespato dominante $(30-40 \%)$, con desarrollo de cristales subhedrales de 0,5 a $2,5 \mathrm{~mm}$ de longitud, con maclado polisintético y fuerte zonación. El núcleo está comúnmente alterado a sericita, que crece en los planos de clivaje, y epidota; en algunos casos también se observa alteración a caolinita. En partes, se reconoce textura en damero (chessboard) y textura mirmequítica de reemplazo, que penetra en el feldespato potásico. Se observan también escasas inclusiones de cuarzo subredondeado y laminillas de micas.

El microclino (15-30\%) se observa en individuos anhedrales de 1 a 2 mm generalmente, con desarrollo de maclas periclino-albita deformadas y discontinuas y es común la presencia de finas venillas pertíticas. Posee inclusiones de cuarzo de formas subredondeadas y plagioclasa subhedral a euhedral. Presenta escasa alteración, principalmente sericítica. 


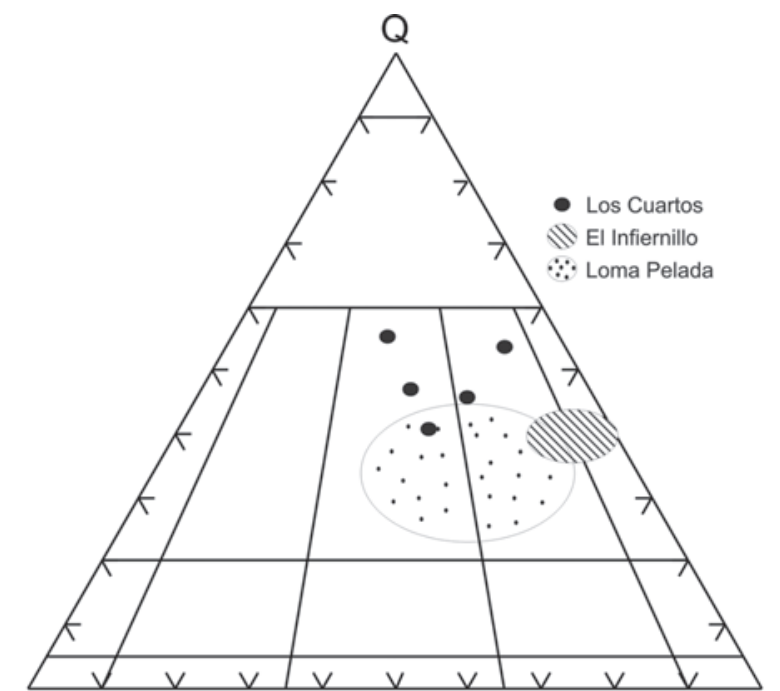

A

Fig. 2.-Diagrama QAP de Streckeisen (1976) con la proyección de las rocas estudiadas.

El cuarzo (30-50\%) se observa en cristales de 0,5 a $5 \mathrm{~mm}$, con abundantes inclusiones de rutilo acicular y a veces de láminas de biotita. Presentan formas anhedrales, con extinción ondulante y bordes angulosos e irregulares.

El principal mineral accesorio es biotita, que se observa en láminas subhedrales de hasta $2 \mathrm{~mm}$ de color pardo, con inclusiones de circón con halos pleocroicos bien definidos y cristales subhedrales de apatito prismático; en algunos presenta alteración a clorita, moscovita y epidota y folias levemente flexuradas, única evidencia de deformación en los constituyentes minerales.

La moscovita primaria, presente en menor cantidad, se observa en láminas subhedrales de 1 a $1,5 \mathrm{~mm}$ de longitud, intersticial o como inclusiones en los minerales félsicos. También se reconoce moscovita secundaria asociada a biotita.

Otro mineral presente es la titanita, en cristales de hasta $0,7 \mathrm{~mm}$ y de forma subhedral.

\section{Otros granitoides de la región}

A fin de establecer relaciones comparativas con el Granito Los Cuartos, se consideran sintéticamente los plutones de El Infiernillo y Loma Pelada, relacionados entre sí tanto por su emplazamiento a lo largo de la Megafractura de Tafí como por sus rasgos geotectónicos, petrográficos, geoquímicos y geocronológicos (Toselli et al., 1985).
El plutón de El Infiernillo está formado principalmente por granodioritas y en menor proporción tonalitas, de dos micas con epidota; el cuarzo presenta estructuras cataclásticas y son comunes los núcleos de clinozoicita en plagioclasa, mientras que la pistasita está asociada a biotita. La roca de caja corresponde a metamorfitas de grado medio Toselli et al., 1985).

El intrusivo de Loma Pelada presenta como facies dominante granodioritas de dos micas, con biotita y plagioclasa zonada, con núcleo andesítico y borde oligoclásico y granitos moscovíticos que forman diques que penetran la granodiorita; la plagioclasa es homogénea (oligoclasa-albita), el microclino es tardío, intersticial e incluye tablillas de plagioclasa (Saavedra et al., 1984).

\section{Geoquímica}

Los análisis químicos del Granito Los Cuartos se realizaron sobre roca total en la Universidad Nacional de Salta (Argentina). El método utilizado corresponde a fluorescencia de rayos X (XRF) (tabla 1). Los datos químicos de los otros cuerpos graníticos fueron recopilados de la bibliografía existente (Saavedra et al., 1984; Toselli et al., 1985; Pérez, 1987; Lisiak, 1990).

En el diagrama AFM (fig. 3) se representaron las rocas correspondientes al Granito Los Cuartos conjuntamente con los intrusivos de Loma Pelada y El Infiernillo (Toselli et al., 1988). Se aprecia una típica tendencia calco-alcalina para el magma-

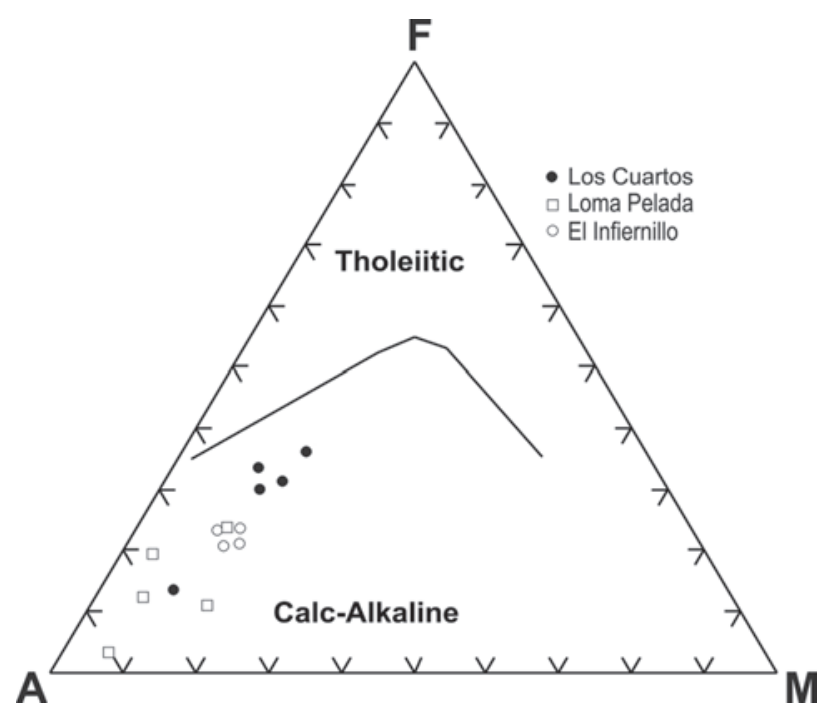

Fig. 3.-Diagrama AFM (Irvine \& Baragar, 1971). 
Tabla 1.-Análisis químicos de elementos mayores, menores (expresados en peso \%) y trazas (expresados en ppm)

\begin{tabular}{|c|c|c|c|c|c|c|c|c|c|c|c|c|c|c|}
\hline & \multicolumn{5}{|c|}{ Los cuartos } & \multicolumn{5}{|c|}{ Loma Pelada } & \multicolumn{4}{|c|}{ El Infiernillo } \\
\hline & 224 & 169 & 89 & 231 & 5 & LP-1 & LP-4 & LP-36 & LP-40 & LP-13 & 3896 & 3895 & 3903 & 3898 \\
\hline $\mathrm{SiO}_{2}$ & 66,71 & 66,24 & 75,48 & 64,89 & 65,51 & 72,86 & 72,98 & 74,58 & 74,75 & 73,36 & 72,80 & 70,36 & 68,00 & 69,94 \\
\hline $\mathrm{TiO}_{2}$ & 0,66 & 0,63 & 0,26 & 0,78 & 0,73 & 0,23 & 0,20 & 0,06 & 0,05 & 0,05 & 0,40 & 0,48 & 0,49 & 0,54 \\
\hline $\mathrm{Al}_{2} \mathrm{O}_{3}$ & 14,86 & 15,45 & 12,40 & 15,43 & 14,91 & 14,27 & 13,68 & 13,97 & 14,38 & 14,58 & 14,37 & 14,87 & 17,97 & 15,56 \\
\hline $\mathrm{Fe}_{2} \mathrm{O}_{3}$ & 5,11 & 4,63 & 1,97 & 5,38 & 5,63 & 2,43 & 1,73 & 1,51 & 2,68 & 0,00 & 2,45 & 2,91 & 2,90 & 3,11 \\
\hline $\mathrm{MnO}$ & 0,08 & 0,08 & 0,04 & 0,08 & 0,76 & 0,02 & 0,02 & 0,03 & 0,02 & 0,02 & 0,06 & 0,06 & 0,08 & 0,07 \\
\hline $\mathrm{MgO}$ & 2,10 & 1,72 & 0,88 & 1,81 & 2,40 & 1,12 & 1,48 & 0,72 & 0,56 & 0,48 & 0,84 & 1,06 & 1,11 & 1,13 \\
\hline $\mathrm{CaO}$ & 1,81 & 2,31 & 0,30 & 2,77 & 2,07 & 1,57 & 1,34 & 0,34 & 0,44 & 0,34 & 2,29 & 2,60 & 3,38 & 3,04 \\
\hline $\mathrm{Na}_{2} \mathrm{O}$ & 2,87 & 2,88 & 2,18 & 2,87 & 2,63 & 3,58 & 4,21 & 3,65 & 3,55 & 3,80 & 3,29 & 3,45 & 3,85 & 3,10 \\
\hline $\mathrm{K}_{2} \mathrm{O}$ & 3,84 & 4,35 & 4,97 & 3,85 & 3,62 & 2,33 & 2,35 & 3,50 & 4,45 & 3,45 & 1,92 & 2,59 & 1,81 & 1,64 \\
\hline $\mathrm{P}_{2} \mathrm{O}_{5}$ & 0,23 & 0,34 & 0,17 & 0,31 & 0,21 & 0,23 & 0,17 & 0,07 & 0,03 & 0,04 & 0,05 & 0,21 & 0,20 & 0,38 \\
\hline LOI & 1,29 & 0,87 & 0,87 & 0,88 & 1,20 & 0,52 & 0,80 & 0,46 & 0,70 & 0,36 & 0,62 & 0,68 & 0,71 & 0,60 \\
\hline TOTAL & 99,55 & 99,51 & 99,51 & 99,05 & 99,67 & 99,36 & 99,54 & 99,11 & 100,44 & 99,14 & 99,09 & 99,27 & 100,50 & 99,11 \\
\hline $\mathrm{Rb}$ & 124 & 147 & 130 & 124 & 122 & 115 & 125 & 210 & 210 & 300 & 82 & 81 & 58 & 60 \\
\hline $\mathrm{Ba}$ & 608 & 488 & 697 & 592 & 603 & 230 & 215 & 50 & 50 & 50 & 145 & 300 & 220 & 195 \\
\hline $\mathrm{Sr}$ & 210 & 147 & 207 & 189 & 190 & 185 & 155 & 32 & 28 & 16 & 180 & 198 & 280 & 340 \\
\hline $\mathrm{Nb}$ & 10 & 12 & 5 & 11 & 12 & & & & & & & & & \\
\hline $\mathrm{Zr}$ & 266 & 233 & 159 & 288 & 259 & 111 & 93 & 26 & 23 & 24 & 210 & 234 & 145 & 142 \\
\hline $\mathrm{Y}$ & 34 & 32 & 26 & 24 & 35 & 12 & 11 & 15 & 14 & 12 & 10 & 11 & 8 & 10 \\
\hline
\end{tabular}

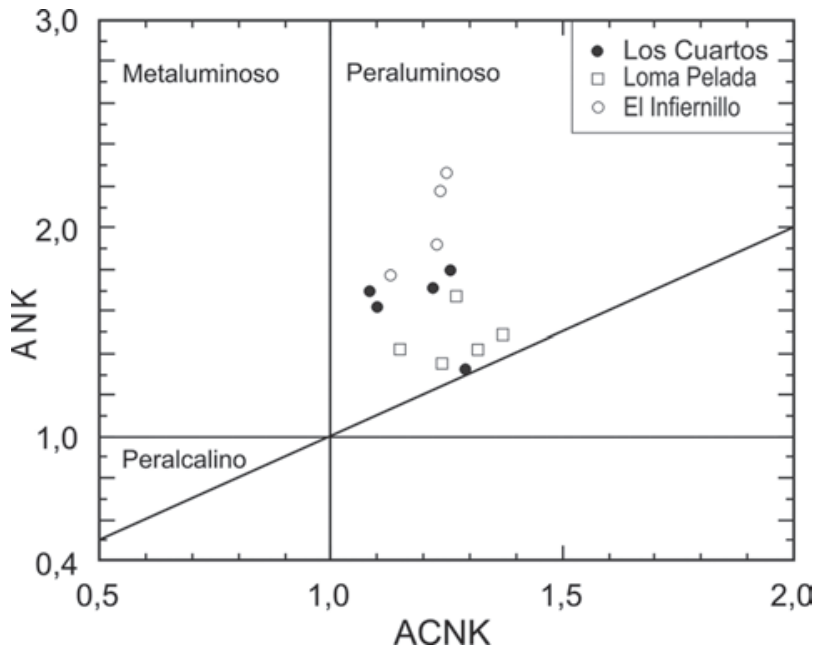

Fig. 4.-Diagrama de Maniar \& Piccoli (1989) utilizando los índices de Shand.

tismo en esta zona. El Granito Los Cuartos es de característica peraluminosa con un índice de saturación en alúmina (ISA) entre 1,11 y 1,30 (fig. 4). Esto también se refleja en el diagrama AB (Debon $\&$ Le Fort, 1983) en donde las muestras se proyectan principalmente en el campo moderadamente peraluminoso (fig. 5). Los granitos de Loma Pela-

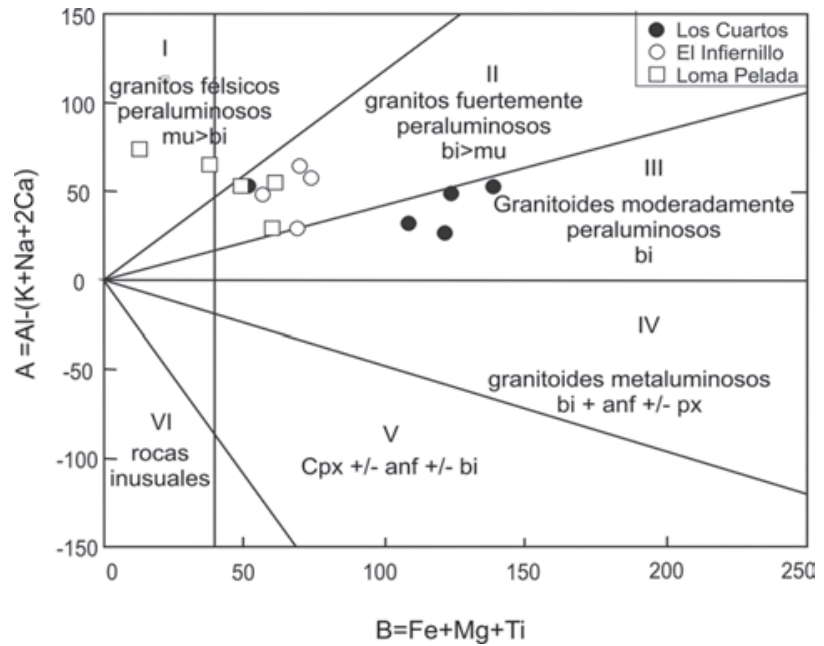

Fig. 5.-Diagrama de discriminación de Debon \& Le Fort (1983).

da y El Infiernillo, al igual que el granito estudiado, presentan características peraluminosas (Toselli et al., 1988).

En los diagramas de variación de óxidos y trazas vs. $\mathrm{SiO}_{2}$ (figs. 6 y 7 ) se observa que el granito Los Cuartos corresponde a las rocas menos evolucionadas de la tendencia general. Los diagramas de 

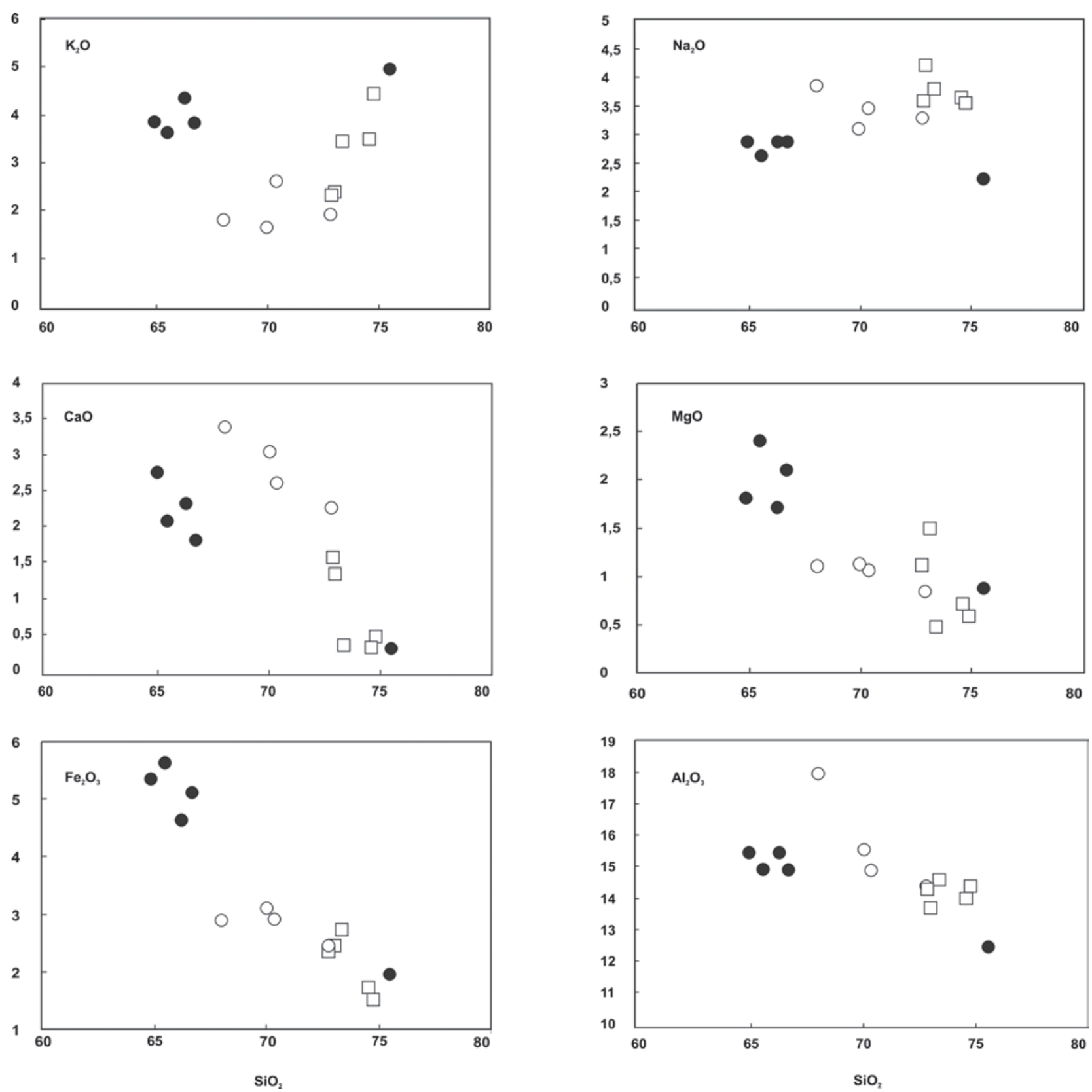

Fig. 6.-Diagramas de variación de elementos mayores vs. $\mathrm{SiO}_{2}$.

$\mathrm{Al}_{2} \mathrm{O}_{3}, \mathrm{TiO}_{2}, \mathrm{CaO}, \mathrm{Fe}_{2} \mathrm{O}_{3}, \mathrm{MgO}$ y $\mathrm{MnO}$ muestran una buena correlación negativa con la $\mathrm{SiO}_{2}$, mientras que los demás óxidos presentan una mayor dispersión.

En el diagrama normativo Ab-An-Or (Barker, 1979) puede observarse una diferenciación entre los tres granitoides estudiados, con cierta afinidad trondhjemítica para el Granito de Loma Pelada (fig. 8).

\section{Interpretación y conclusiones}

El Granito Los Cuartos de características peralumínicas, rico en $\mathrm{K}$ y $\mathrm{P}$, y con contenidos comparativamente más bajos en $\mathrm{Ca}$ y $\mathrm{Na}$ que los granitoides del área, podrían tener una mayor participación de componentes corticales en su génesis, que habría que precisar en trabajos futuros, involucrando datos 

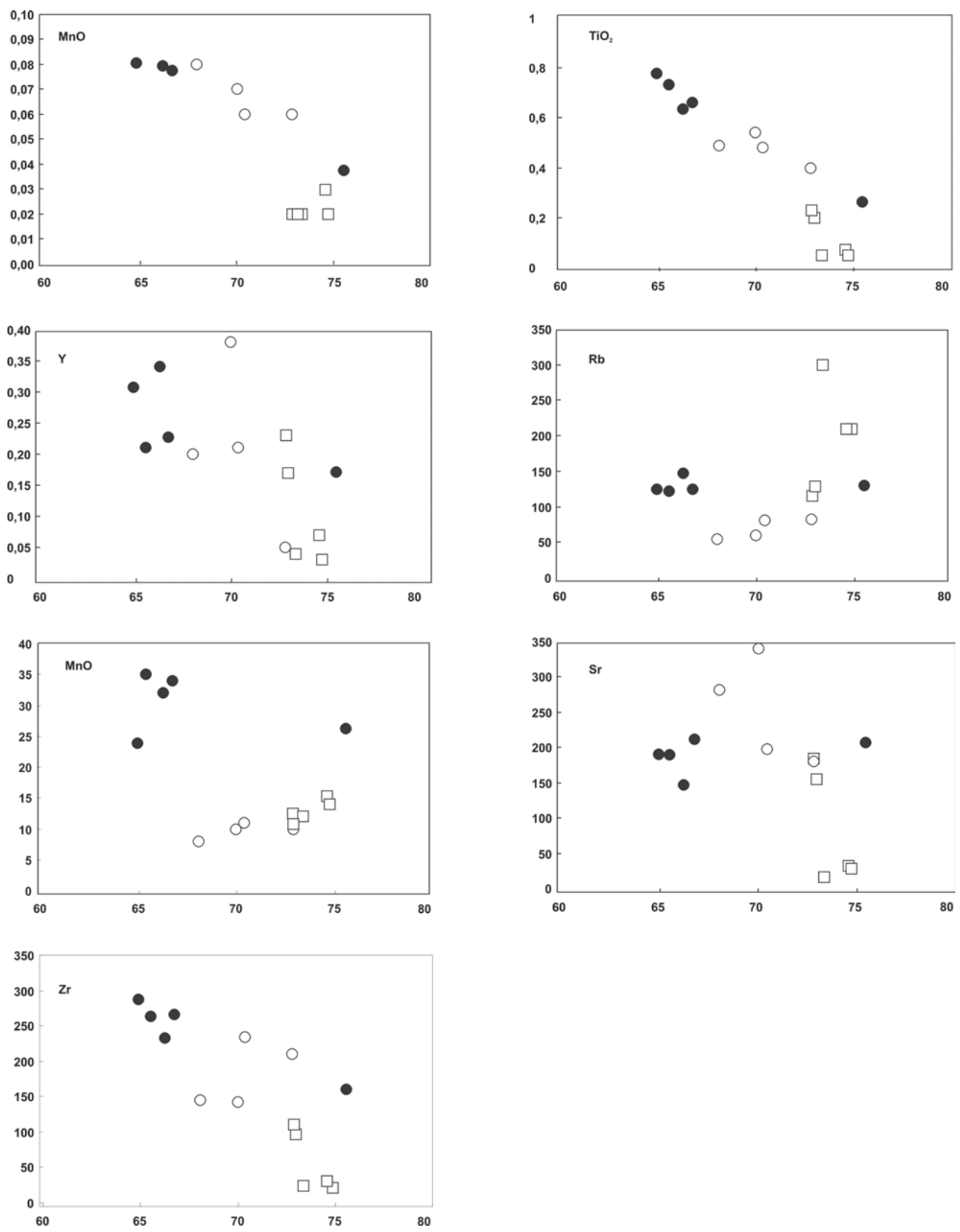

Fig. 7.-Diagramas de variación de elementos menores y trazas vs. $\mathrm{SiO}_{2}$.

Estudios Geol., 66(2), 147-156, julio-diciembre 2010. ISSN: 0367-0449. doi:10.3989/egeol.40051.083 


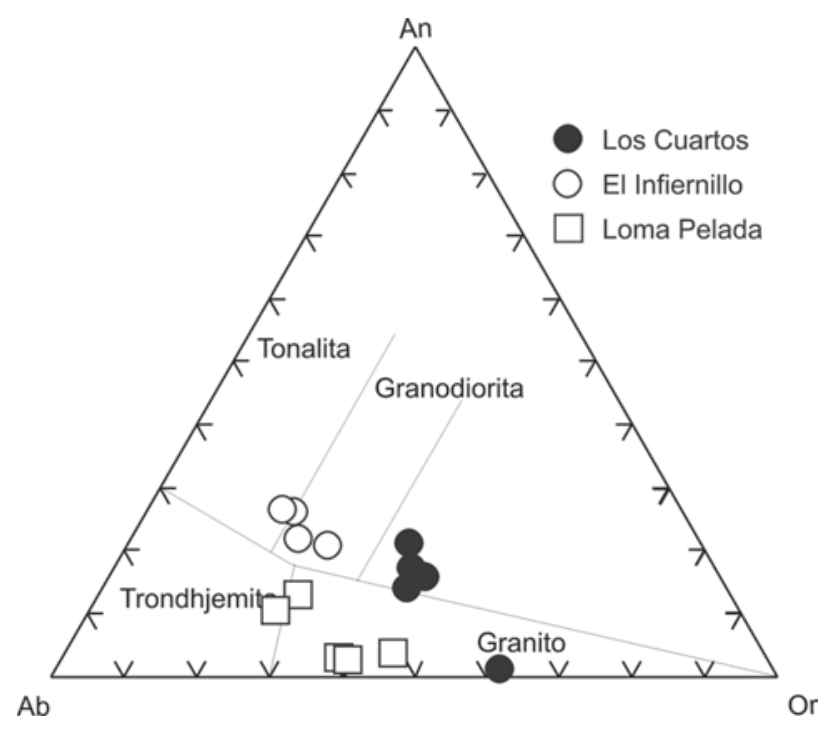

Fig. 8.-Diagrama de Baker (1979).

isotópicos. El stock El Infiernillo es esencialmente granodiorítico de dos micas (Lisiak, 1990) y el intrusivo de Loma Pelada está compuesto por granitos de dos micas y moscovíticos. El emplazamiento y cristalización de estos granitos sería superficial, de características tardías a postectónicas con respecto a la deformación y el ascenso del magma estaría relacionado con una zona de fallamiento distensivo. El emplazamiento de los plutones de El Infiernillo y Loma Pelada estarían estructuralmente controlado por la Megafractura de Tafí (Toselli et al., 1989) mientras que el Granito Los Cuartos no presenta evidencias de tal control estructural.

En este contexto, el Granito Los Cuartos presenta ciertas características comunes y otras distintivas respecto al resto de los intrusivos de la región. Es de composición granítica a granodiorítica de dos micas, calcoalcalino, peraluminoso y desarrolla metamorfismo de contacto con formación de andalucita en la roca encajante. Pertenecería al grupo de granitoides tardíos D2 de Sierras Pampeanas Orientales de acuerdo a la clasificación de Rapela et al. (1990).

La intrusión del Granito Los Cuartos habría afectado al basamento metamórfico de la región, generando el desarrollo de una blastesis estática que se sobreimpone a la fábrica esquistosa anterior. Así se produce el desarrollo de andalucita en las inmediaciones del cuerpo ígneo y de biotita poiquiloblástica, en una zona más alejada.

Edades de este cuerpo granítico fueron determinadas por González et al. (1973) por el método K/Ar en biotita, obteniendo valores entre $479 \pm 9$ y
$456 \pm 21 \mathrm{Ma}$, que son consistentes con las edades obtenidas por Toselli et al. (1985) para el resto de los intrusivos de la zona (507 a $415 \mathrm{Ma})$. Según estos autores, las edades mayores (507 a $460 \mathrm{Ma}$ ) corresponderían a la cristalización más antigua (granodioritas de dos micas) mientras que las edades más jóvenes (424-446 Ma) corresponderían a los granitos moscovíticos más evolucionados. Sales et al. (1998) determinaron para el Granito Loma Pelada una edad de $470 \pm 10 \mathrm{Ma}$ por el método $\mathrm{Rb} / \mathrm{Sr}$ en roca total. El conjunto de dataciones coincide con los resultados obtenidos por Bachmann et al. (1985), que determinan por el método $\mathrm{Rb} / \mathrm{Sr}$, que las metamorfitas encajantes tienen edades de 557-569 Ma para el primer evento metamórfico sincinemático y 459-470 Ma para el segundo, de tipo esencialmente térmico, relacionado con el Ciclo Famatiniano.

Toselli et al. (1997) en base a características isotópicas tales como las relaciones iniciales ${ }^{87} \mathrm{Sr} /{ }^{86} \mathrm{Sr}$ y $\varepsilon N d$ para los granitos El infiernillo y Loma Pelada, indican que en la génesis de los magmas hubo una mezcla entre componentes corticales y mantélicos. Asimismo, Sales et al. (1998) obtienen una relación inicial ${ }^{87} \mathrm{Sr} /{ }^{86} \mathrm{Sr}$ para el Granito Loma Pelada de 0,7058 llegando a una conclusión similar. Por el momento no disponemos de información isotópica respecto del Granito de Los Cuartos y no se encontraron evidencias, tales como enclaves máficos que sugieran para este plutón implicaciones genéticas similares.

\section{AGRADECIMIENTOS}

El presente trabajo fue financiado por el proyecto CIUNT 26/G427. Los autores agradecen a los Dres. Raúl Becchio y Pablo Grosse por su valiosa colaboración y al Dr. Carlos Villaseca por las valiosas correcciones recibidas.

\section{Referencias}

Aceñolaza, F.G. \& Toselli, A.J. (1976). Consideraciones estratigráficas y tectónicas sobre el Paleozoico Inferior del Noroeste Argentino. II Congreso latinoamericano de Geología, Caracas, 2: 755-763.

Bachmann, G.; Grauert. B. \& Miller, H. (1985). Isotopic dating of polymetamorphic metasediment from NW Argentina. Zentralblatt F ür Geologie und Paläontologie, Teil I: 1257-1268.

Baldis, B.; Viramonte, J. \& Salfity, J. (1975). Geotectónica de la comarca comprendida entre el Cratógeno Central Argentino y el borde austral de la Puna. II Congreso Iberoamericano de Geología Económica, Buenos Aires, 4: 25-44. 
Barker, F. (1979). Trondhjemite definition, environment and hypothesis of origin. In: Trondhjemites, dacites \& related rocks (Barker, F., ed.). Elsevier, New York, $1-12$.

Caminos, R. (1979). Sierras Pampeanas Noroccidentales, Salta, Tucumán, Catamarca, La Rioja y San Juan. II Simposio Geología Regional Argentina, Academia Nacional de Ciencias de Córdoba, I: 225-291.

Debon, F. \& Le Fort, P. (1983). A chemical-mineralogical classification of common plutonic rocks and association. Transaction of the Royal Society of Edinburgh: Earth Sciences, 73: 135-149.

González, R.; Toselli, A.J. \& Soria, B. (1973). Edades Potasio-Argón de algunos granitos de las Cumbres Calchaquíes, Provincia de Tucumán. Acta Geológica Lilloana, 12: 61-70.

Gutiérrez, A. \& Mon, R. (2004). Megageomorfología del valle de Tafí-Aconquija, Tucumán. Revista de la Asociación Geológica Argentina, 59: 303-311.

Irvine, T.N. \& Baragar, W.R.A. (1971). A guide to the chemical classification of the common volcanic rocks. Canadian Journal of Earth Sciences, 8: 523-548.

Kretz, R. (1983). Symbols for rock-forming minerals. American Mineralogist, 68: 277-279.

Lisiak, J.H. (1990). Petrografía y geoquímica de las granodioritas de El Infiernillo, Sierra del Aconquija, Tucumán, Argentina. XI Congreso Geológico Argentino, San Juan, 1: 68-71.

Maniar, P.D. \& Piccoli, P.M. (1989). Tectonic discrimination of granitoids. Geological Society of America Bulletin, 101: 635-643. doi:10.1130/00167606(1989)101<0635:TDOG>2.3.CO;2

Pankhurst, R.J.; Rapela, C.W. \& Fanning, M.C. (2000). Age and origin of coeval TTG, I- and S- type granites in the Famatinian Belt of NW Argentina. Transactions of the Royal Society of Edinburgh. Earth Sciences, 91: 151-168.

Pérez, A. (1987). Contribución al conocimiento geológico de la zona de La Angostura con especial referencia a las rocas graníticas, departamento Tafí, provincia de Tucumán. Trabajo de Seminario Final, Universidad Nacional de Tucumán, 62 pp.

Rapela, C.W.; Coira, B.; Toselli, A.J. \& Saavedra, J. (1992). The Lower Paleozoic magmatism of southwestern Gondwana and the evolution of the Famatinian Orogene. International Geology Review, 34: 1081-1142. doi:10.1080/00206819209465657

Rapela, C.W.; Toselli, A.J.; Heaman, L. \& Saavedra, J. (1990). Granite Plutonism of the Sierras Pampeanas; An inner cordilleran Paleozoic arc in the Southern Andes. In: Plutonism from Antarctica to Alaska (Rapela, C.W. \& Kay, S., eds.), The Geological Society of America, special Paper, 241: 77-90.

Rossi de Toselli, J.N.; Saavedra, J. \& Toselli, A.J. (1982). Sobre el origen de los niveles calcosilicáticos en el basamento pre-Ordovícico metamorfizado del Cratóge- no Central Pampeano, Argentina. V Congreso Latinoamericano de Geología, 4: 285-296.

Saavedra, J.; Toselli, A.J. \& Rossi de Toselli, J.N. (1984). Aspectos Geológicos y geoquímicos del granito peralumínico de Loma Pelada, Tafí del Valle, Tucumán, Argentina. Revista Asociación Geológica Argentina, 39: 121-27.

Sales, A.; Petronilho, L. \& Kawashita, K. (1998). Datación de la edad geocronológica de rocas graníticas mediante el uso de un Spike combinado Rubidio/Estroncio. Información Tecnológica, 9: 379-386.

Streckeisen, A. (1976). To each plutonic rocks its proper name. Earth-Sciences Reviews, 12: 1-33. doi:10.1016/0012-8252(76)90052-0

Toselli, A.J. (1992). El magmatismo del Noroeste Argentino. Reseña sistemática e interpretación. Serie de Correlación Geológica, $n^{\circ}$ 8, INSUGEO, 243 pp.

Toselli, A.J. \& Rossi de Toselli, J.N. (1973). Metamorfismo de las Cumbres Calchaquíes I: Rasgos de deformación y blastesis en las rocas del faldeo suoccidental entre La Angostura y Tafí del Valle, Tucumán, Rep. Argentina. Revista Asociación Geológica Argentina. 28: 45-55.

Toselli, A.J. \& Rossi de Toselli, J.N. (1984). Metamorfismo de las Cumbres Calchaquíes: II Petrología del basamento esquistoso entre La Angostura y Tafí del Valle, Tucumán. Revista de la Asociación Geológica Argentina, 39: 262-275.

Toselli, A.J.; Rossi de Toselli, J.N.; Saavedra, J. \& Pellitero, E. (1985). Los granitoides de la Megafractura de Tafí, Tucumán, Argentina. Comunicaciones, Chile, 35: 237-241.

Toselli, A.J.; Rossi de Toselli, J.N.; Saavedra, J. \& Pellitero, E. (1989). Granitoids of the Tafí Megafracture (Sierras Pampeanas, Argentina): Petrogenetic implications. Journal of South American Earth Science, 2: 199-204. doi:10.1016/0895-9811(89)90047-3

Toselli, A.J.; Saavedra, J. \& López, J.P. (1997). Magmatic Epidote-Bearing and Cordierite-Bearing Granitoids from NW Argentina. Second International Symposyum Granites and Associated Mineralization, 79-104.

Willner, A. (1990). División tectonometamórfica del basamento de Noroeste Argentino. In: El Ciclo Pampeano en el Noroeste Argentino (Aceñolaza, G.; Miller, H. \& Toselli, A.J., eds.). Serie Correlación Geológica, 4: 113-159.

Willner, A. \& Miller, H. (1986). Structural division and evolution of the Lower Paleozoic Basement in the NW Argentine Andes. Zentral Blatt fur Geologie und Palaontologie, I: 1245-1255.

Winkler, H. (1967). Petrogénesis de rocas metamórficas. Blume Ediciones, Madrid, 346 pp.

Recibido el 26 de agosto de 2009 Aceptado el 20 de abril de 2010 Publicado online el 4 de noviembre de 2010 


\title{
Caracterización petrográfica y geoquímica y condiciones de deformación del plutón San Cristóbal, Sierra de Velasco, La Rioja, Argentina

\author{
Petrographical and geochemical characterization and deformation \\ conditions of the San Cristóbal pluton, Sierra de Velasco, \\ La Rioja, Argentina
}

\author{
L.I. Bellos ${ }^{1}$, A.J. Toselli ${ }^{1}$, J.N. Rossi ${ }^{1}$, P. Grosse ${ }^{2}$, J.D. de la Rosa ${ }^{3}$, A. Castro ${ }^{3}$
}

RESUMEN

El plutón San Cristóbal constituye un cuerpo granítico de $35 \mathrm{~km}^{2}$ que aflora en el extremo sudeste de la Sierra de Velasco, situada al oeste de la ciudad de La Rioja, Argentina. Está formado por monzogranitos y sienogranitos con escasas granodioritas, de texturas equigranulares de grano medio a fino a ligeramente porfíricas. La asociación mineral es cuarzo + microclino + plagioclasa + biotita \pm moscovita + circón + apatito + magnetita. Contiene enclaves magmáticos máficos de composición diorítica a tonalítica. El granito fue afectado en su parte media y este por una zona de cizalla, formada por milonitas que integran la Faja Milonítica Sur, de rumbo NNO-SSE. La roca de caja se reconoce por xenolitos de esquistos y cuarcitas en facies esquistos verdes, y septos de corneanas con la paragénesis feldespato potásico - cordierita - biotita \pm sillimanita. Los granitos son calcoalcalinos, débil a moderadamente peraluminosos, emplazados en un ambiente de arco magmático continental desarrollado en el borde occidental de Gondwana durante el Paleozoico Inferior. La profundidad de emplazamiento del plutón estaría en el orden de los $12 \mathrm{~km}$.

Palabras clave: granitos, plutón San Cristóbal, Faja Milonítica Sur, deformación, Sierra de Velasco, Arco Famatiniano.

\begin{abstract}
The San Cristóbal pluton is a $35 \mathrm{~km}^{2}$ granitic body that outcrops at the southestern tip of the Sierra de Velasco, located west of La Rioja city, Argentina. It is formed by monzogranites and syenogranites, together with scarce granodiorites, with medium to fine-grained, equigranular to slightly porphyritic textures. Their mineral assemblage consists of quartz + microcline + plagioclase + biotite \pm muscovite + zircon + apatite + magnetite. The granite contains dioritic to tonalitic mafic enclaves. The central and eastern parts of the granite have been deformed by the NNW-SSE trending South Mylonitic shear zone formed by mylonitic rocks. The metamorphic host-rock is represented by scarce greenschist facies xenoliths and hornfels with the high T/P assemblage K-feldspar - cordierite - biotite \pm sillimanite. The granites are calc-alkaline, weak- to moderately peraluminous, and formed as part of a continental magmatic arc developed along the active margin of western Gondwana during the Early Paleozoic. The depth of emplacement of the San Cristóbal pluton is estimated at $\sim 12 \mathrm{~km}$.
\end{abstract}

Key words: granites, San Cristóbal pluton, South Mylonitic shear zone, deformation, Sierra de Velasco, Famatinian Arc.

\footnotetext{
1 INSUGEO-CONICET, Facultad de Ciencias Naturales e IML, UNT. Miguel Lillo 205. CP 4000. San Miguel de Tucumán. Argentina. Email: laubel@csnat.unt.edu.ar

2 CONICET, Fundación Miguel Lillo, Miguel Lillo 251. CP 4000. San Miguel de Tucumán. Argentina.

3 Departamento de Geología, Universidad de Huelva, E21071, Huelva, España.
} 


\section{Introducción}

La Sierra de Velasco constituye el mayor afloramiento plutónico de las Sierras Pampeanas y se encuentra ubicada al oeste de la ciudad de La Rioja. Se extiende a lo largo de $180 \mathrm{~km}$ aproximadamente en sentido N-S y presenta una alta relación de afloramientos granito/roca de caja, formando parte de la Zona Batolítica Central, definida por Toselli et al. (1986).

Esta sierra está conformada por numerosos plutones con edades que van desde el Ordovícico al Carbonífero Inferior (Rapela et al., 2001; Grosse et al., 2003; Báez et al., 2004; Grosse \& Sardi, 2005; Báez \& Basei, 2005; Báez, 2006; Dahlquist et al., 2006; Toselli et al., 2007; Grosse et al., 2009). Algunos de estos plutones fueron afectados por procesos deformativos que generaron varias zonas de cizalla de rumbo general NNO-SSE constituidas por rocas miloníticas y cataclásticas, con diferentes grados de deformación (López et al., 1996, 2007; López, 2005).

El plutón San Cristóbal constituye un intrusivo granítico de $35 \mathrm{~km}^{2}$, con una relación largo/ancho de 0,75 , que aflora en el extremo sudeste de la Sierra de Velasco (fig. 1), formando parte del Batolito Patquía que está integrado además por los plutones Palanche y Antinaco (Toselli et al., 2007; Bellos, 2008).

Una faja de cizalla de $2,5 \mathrm{~km}$ de ancho y rumbo NNO-SSE, denominada Faja Milonítica Sur, deformó a los plutones Palanche y San Cristóbal, originando rocas miloníticas y cataclásticas.

El objetivo de este trabajo es describir detalladamente la petrografía y las características geoquímicas generales de los granitos que conforman el plutón San Cristóbal así como las condiciones físicas de su emplazamiento; y además, caracterizar petrográfica y estructuralmente a las rocas que componen la Faja Milonítica Sur.

\section{Antecedentes y marco geológico del sector austral de la Sierra de Velasco}

Los primeros trabajos enfocados específicamente en las rocas graníticas del sector sudoccidental de la Sierra de Velasco corresponden a Bellos (2000) y Grosse (2000). Bellos (2000) describe la presencia, al oeste del Bolsón de Paluqui, de granodioritas y tonalitas biotíticas y/u hornbléndicas y monzogranitos subordinados, con enclaves ígneos máficos.
Estas rocas fueron afectadas por una estrecha faja de deformación dúctil que generó rocas miloníticas. Grosse (2000) indica que al NO del Bolsón de Paluqui, además de estos granitoides, se distinguen diques sin-plutónicos y enclaves máficos con fenómenos de mezcla con el granitoide encajante.

Bellos et al. (2002) reconocen las diferencias entre los granitoides del flanco sudoccidental de la sierra y los granitoides del centro y norte de la misma, y su similitud con algunos granitoides del Sistema de Famatina. Así, establecen que las rocas del flanco sudoccidental tienen una composición granodiorítica-tonalítica predominante con monzogranitos subordinados, con tendencias geoquímicas calcoalcalinas, metaluminosas a débilmente peraluminosas. Las granodioritas-tonalitas poseen biotita, titanita \pm hornblenda como accesorios principales. Su vinculación con rocas máficas sugiere que posiblemente en su génesis haya habido participación de la corteza inferior máfica y/o manto superior.

Bellos (2005a y b) publica los primeros trabajos realizados en el sector austral de la Sierra de Velasco, al sur de los $29^{\circ} 44^{\prime}$ latitud sur, mencionando la presencia de granitoides biotítico-hornbléndicos, con rocas máficas asociadas.

Bellos (2008) indica que la parte austral de la Sierra de Velasco está constituida dominantemente por granitoides que conforman dos plutones denominados Palanche y San Cristóbal, los cuales integran el Batolito Patquía. Señala además que el plutón Palanche, de probable edad ordovícica inferior, está constituido por granodioritas y tonalitas biotíticas-hornbléndicas a biotíticas, mientras que variaciones a monzogranitos biotíticos se encuentran en menor proporción. La asociación mineral característica de este plutón es plagioclasa + cuarzo + microclino + biotita \pm hornblenda + titanita + allanita + magnetita. Geoquímicamente estas rocas son metaluminosas a débilmente peraluminosas, de tipo-I. Por su parte, las características de las rocas que conforman el plutón San Cristóbal se presentan detalladamente en este trabajo.

Por otra parte, López et al. (2006) realizan un análisis estructural, petrográfico y comparativo de dos zonas de cizalla presentes en la Sierra de Velasco. Concluyen que la Faja Milonítica TiPA y la Faja Milonítica Sur (la cual afecta a los plutones Palanche y San Cristóbal), contienen rocas de deformación dúctil y frágil, que reflejan movimientos inversos en el dominio dúctil, con desplazamiento tectónico hacia el oeste. 


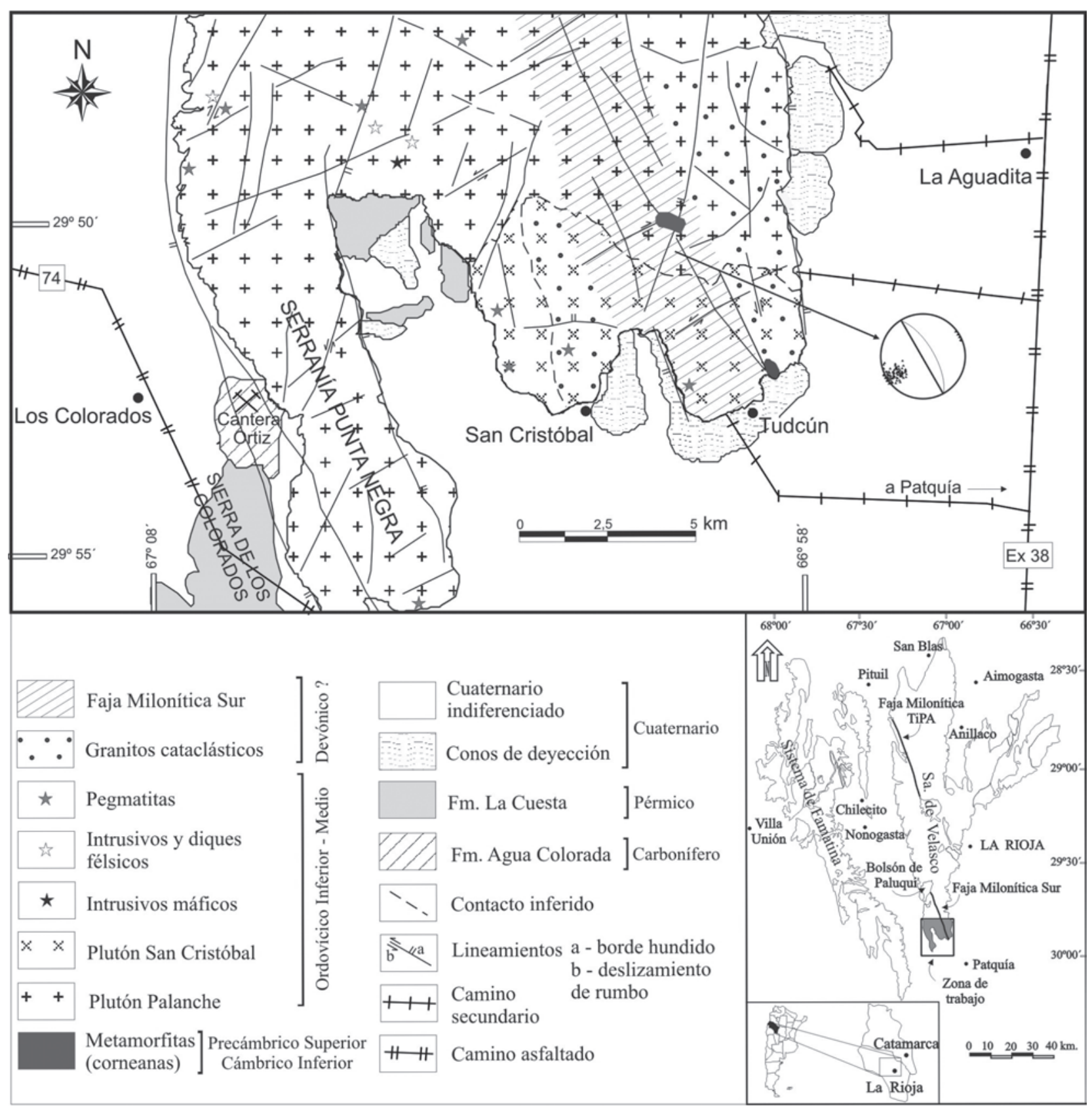

Fig. 1.-Esquema geológico de la zona de estudio.

\section{Petrografía y relaciones de campo del plutón San Cristóbal}

El plutón San Cristóbal aflora en el extremo sudeste de la Sierra de Velasco (fig. 1) y su área de afloramiento ha sido delimitada con la ayuda de imágenes aéreas y satelitales. El contacto con el plutón Palanche, que constituye el cuerpo granítico dominante de la región, es inferido debido a que la espesa cubierta vegetal no permite reconocerlo en el terreno.

La roca de caja de los granitos es muy escasa y se reconoce en xenolitos de esquistos y cuarcitas de facies esquistos verdes, y como pequeños septos de corneanas de forma irregular, generadas por metamorfismo térmico de alta temperatura y baja presión con la paragénesis feldespato potásico - cor- 
dierita - biotita \pm sillimanita. La presencia de sillimanita, junto a cordierita, y la ausencia de granate en las corneanas, indicarían que el metamorfismo ocurrió a temperaturas mayores a $640{ }^{\circ} \mathrm{C}$ y presiones inferiores a los 5 kbar (Bucher \& Frey, 1994; Rossi \& Toselli, 2004).

El plutón San Cristóbal está conformado principalmente por monzogranitos y sienogranitos con escasas granodioritas subordinadas. Este cuerpo fue deformado en su parte media y este, desarrollándose rocas miloníticas y cataclásticas que integran la denominada Faja Milonítica Sur de orientación NNO-SSE (Bellos, 2005b, 2008). Hacia ambos lados de esta faja, las rocas pierden la foliación milonítica característica de las milonitas y protomilonitas, para dar lugar a deformación de tipo frágil que se reconoce sólo microscópicamente. A estas rocas con deformación frágil menos intensa, que constituyen la mayor parte del plutón San Cristóbal, las denominamos granitos cataclásticos. En la parte más occidental del plutón, las rocas no presentan deformación.

El plutón San Cristóbal, al igual que el plutón Palanche, contiene enclaves magmáticos máficos de composición diorítica a tonalítica, con diferentes grados de hibridización.

Tanto los granitos no deformados, como los cataclásticos, son de color gris rosado a blanco grisáceo, equigranulares de grano medio a fino, llegando en algunos casos a ser ligeramente porfíricos con megacristales de feldespato potásico de hasta $2 \mathrm{~cm}$ de largo. La asociación mineral característica es cuarzo + microclino + plagioclasa + biotita \pm moscovita + circón + apatito + magnetita. En general la estructura de estos granitoides es maciza, pero en las cercanías de la zona de cizalla se hace débilmente esquistosa debido a la iso-orientación de láminas de biotita.

La plagioclasa $\left(\mathrm{An}_{11}\right.$ a $\mathrm{An}_{30}, 15-54 \%$ modal $)$ se presenta en cristales de forma anhedral a subhedral en ocasiones zonada o con maclas tipo Albita y Albita-Carlsbad. El cuarzo (22-52\% modal) es anhedral, con bordes irregulares y extinción ondulosa. Algunos cristales presentan fracturas rellenas por pequeños cristales recristalizados, de forma lobulada. El microclino (24-46\% modal) es de forma anhedral, pertítico y con maclas PericlinoAlbita. Posee inclusiones de cuarzo redondeado, plagioclasa y biotita. La biotita (4-12\% modal) es el único mineral accesorio abundante; se presenta con bordes desflecados y alterada en parte a moscovita y epidota. Algunas láminas presentan extinción ondulosa y suaves pliegues.
Como minerales accesorios menores se distingue circón y apatito de hábito prismático y en secciones basales, incluidos en cuarzo, feldespatos y biotita, y magnetita asociada a biotita.

En los granitos cataclásticos la deformación está reflejada en la textura microscópica de la roca. El cuarzo se encuentra rodeado por un mosaico de pequeños cristales con contactos lobulados hasta poligonales y por bandas de granulación generadas por trituración y molienda del mineral (fig. 2A). El microclino presenta maclas y/o pertitas deformadas y mirmequitas en el contacto con plagioclasa (fig. 2B). La plagioclasa es el mineral menos afectado por la deformación, la cual sólo se reconoce por las maclas incompletas, esfumadas y combadas. La deformación de las láminas de biotita es bien notable, presentando extinción ondulosa y kinking. La moscovita en general es escasa y secundaria, aunque en algunos casos puede ser de origen primario asociándose a la biotita y mostrando pliegues kink y extinción ondulosa (fig. 2C). En muestras cercanas a la faja milonítica se reconocieron simplectitas de moscovita -cuarzo y biotitacuarzo (fig. 2D), en los contactos entre cristales y asociadas al microclino. Estas simplectitas podrían haberse formado en respuesta a los esfuerzos deformativos, por circulación de fluidos de baja temperatura y la consecuente hidratación del feldespato alcalino para dar intercrecimientos de moscovita y cuarzo, según la reacción $\mathrm{Kfs}+\mathrm{H}_{2} \mathrm{O}=\mathrm{Ms}+\mathrm{Qtz}$ (Escuder Viruete et al., 2001).

\section{Petrografía de las rocas deformadas de la Faja Milonítica Sur y condiciones de la deformación}

Las rocas deformadas de la Faja Milonítica Sur corresponden a milonitas y protomilonitas de color gris rosado a gris oscuro, de grano fino a medio con textura porfiroclástica dada por porfiroclastos de microclino y plagioclasa de hasta $1 \mathrm{~cm}$ (en algunos casos mayores) rodeados de una matriz cuarzo-micácea con desarrollo de foliación milonítica (fig. 2E).

Los porfiroclastos de plagioclasa y microclino se comportan mayormente de manera frágil, presentando numerosas fracturas y efectos de tracción y desgarro en los bordes (fig. 2F). Comúnmente adoptan formas asimétricas, desarrollando colas de presión (fig. 2G). El microclino presenta maclas Periclino-Albita anómalas o esfumadas y son comunes las mirmequitas y las pertitas que se esfuman 

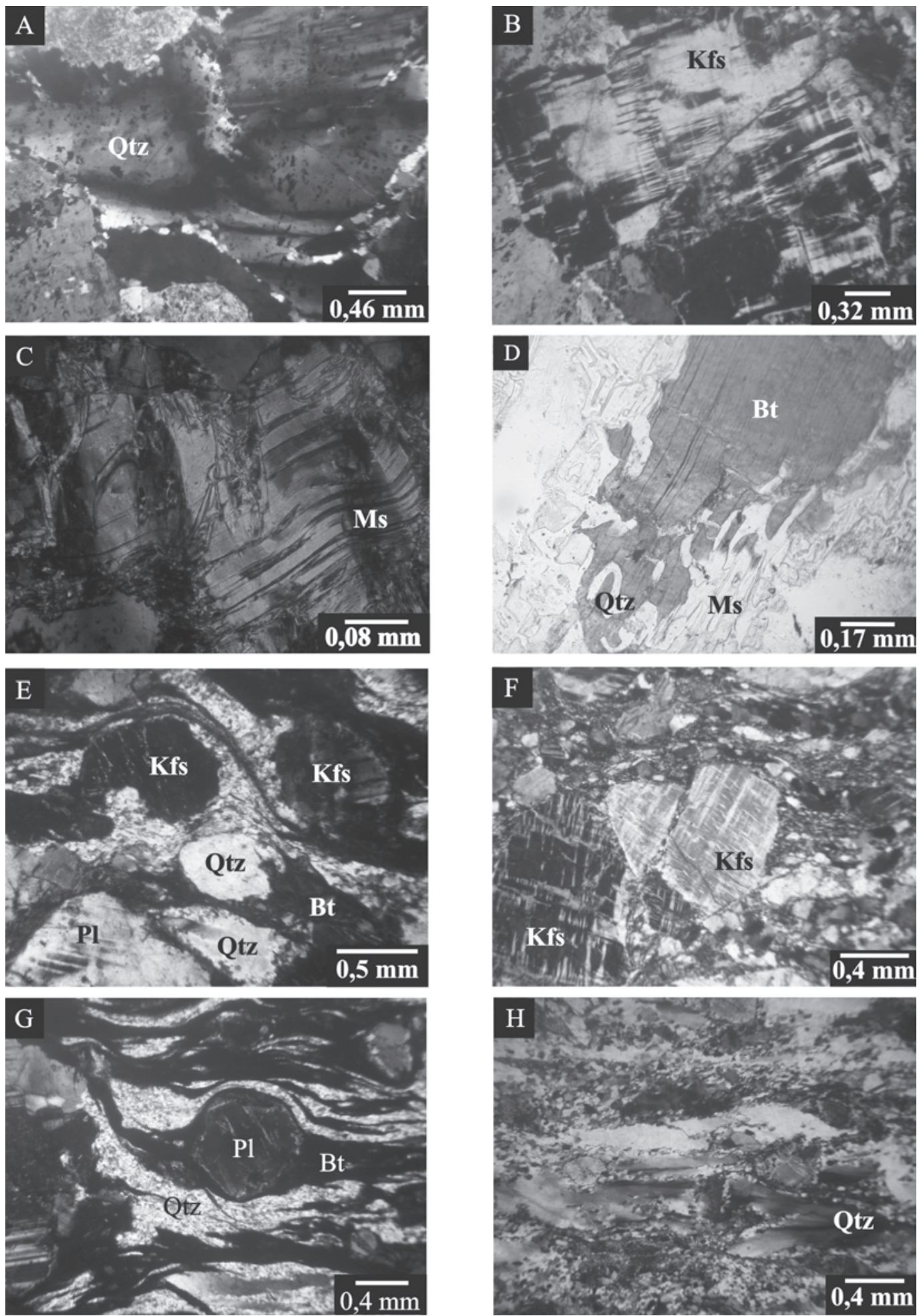

Fig. 2.-Microfotografías del plutón San Cristóbal: A) cristal de cuarzo deformado, con extinción ondulosa rodeado de otros más pequeños de forma lobulada $(\mathrm{N}+)$; B) cristal de microclino fracturado y con maclas esfumadas $(\mathrm{N}+)$; $\mathrm{C}$ ) lámina de moscovita con pliegues kink $(\mathrm{N}+)$; D) lámina de biotita rodeada de simplectitas ms-qtz y bt-qtz (N//). Microfotografías de las rocas miloníticas: E) porfiroclastos en una mesostasis con desarrollo de foliación milonítica $(\mathrm{N}+)$; F) porfiroclasto de microclino con un borde con tracción y desgarro $(\mathrm{N}+)$; G) porfiroclasto de plagioclasa con estructura asimétrica rodeado por biotita y cuarzo que desarrollan la foliación milonítica $(\mathrm{N}+)$; $\mathrm{H})$ cuarzo con extinción lamelar rodeados por pequeños blastos recristalizados dinámicamente $(\mathrm{N}+)$. 
hacia el centro del grano. La plagioclasa, intensamente alterada a sericita, epidota y calcita, se encuentra zonada, o con maclas Albita o AlbitaCarlsbad esfumadas, combadas o acuñadas. El cuarzo se presenta como cristales relícticos de forma sigmoidal, con extinción fragmentosa, ondulosa o lamelar. También forma subgranos que pasan lateralmente a un mosaico recristalizado dinámicamente, formado por pequeños cristales de formas lobuladas o suturadas, ligeramente orientados (fig. $2 \mathrm{H}$ ). En algunos casos se observan cristales poligonales productos de recristalización postcinemática. Entre las bandas recristalizadas dinámicamente y en los bordes de los porfiroclastos es común el desarrollo de delgadas bandas con textura de mortero. Las láminas de biotita (en general moscovitizadas o cloritizadas) se encuentran orientadas, marcando la foliación milonítica. Presentan en ocasiones forma sigmoidal (mica fish), acodada y pliegues kink. En algunos casos se observan simplectitas de moscovita-cuarzo, generadas por la cizalla.

Por otra parte, dentro de la faja de cizalla se encuentran también cataclasitas sin poder observarse un contacto definido con las milonitas. Mineralógicamente son similares a éstas, pero presentan predominio de texturas frágiles sobre las dúctiles y ausencia de foliación milonítica. Presentan color gris rosado y tamaño de grano medio a grueso. Son abundantes los porfiroclastos de microclino y plagioclasa anhedrales, fracturados, rodeados por una matriz de cuarzo y escasa biotita. Los porfiroclastos de ambos feldespatos presentan bordes irregulares y angulosos y las texturas intracristalinas características son extinción fragmentosa, lamelar y ondulosa, recristalización dinámica parcial del cuarzo, textura de mortero y bordes desflecados en micas.

Las condiciones físicas de la deformación se pueden establecer en base a la fábrica de las rocas deformadas y a su mineralogía. Passchier \& Trouw (1996) relacionan las microestructuras de las rocas graníticas deformadas con el grado metamórfico. Así, mencionan que en condiciones de metamorfismo de bajo grado, los feldespatos se comportan de manera frágil, mientras que el cuarzo y las micas se deforman dúctilmente. Los feldespatos pueden presentarse como porfiroclastos manteados, envueltos por cuarzo que se deforma homogéneamente; el centro de cristales antiguos de cuarzo forma subgranos que lateralmente pasan a granos recristalizados. Por lo tanto, la deformación en la Faja Milonítica Sur correspondería a condiciones de facies esquistos verdes (Bellos, 2005, 2008).

\section{Estructura de las rocas miloníticas}

Los planos de foliación milonítica presentan un rumbo dominante NNO-SSE, con inclinaciones de alto ángulo al NE, la media estadística es N333/69 NE. Estos planos son coincidentes con las mediciones obtenidas en otras zonas de cizalla de la Sierra de Velasco y en sierras aledañas, lo cual sugiere una formación contemporánea de las fajas de cizalla (López et al., 2006). En el noroeste de la sierra, la Faja Milonítica TiPA presenta planos de foliación milonítica con una dirección NNO-SSE (N330-340 $)$ con inclinaciones entre 50 y $75^{\circ}$ hacia el NE (López, 2005). Este rumbo se mantiene en las sierras vecinas de Paimán y Copacabana (Pérez et al., 1991; López, 1998).

En la Faja Milonítica Sur, la lineación milonítica que corresponde a direcciones de estiramiento mineral, posee en general inmersión variable entre 42 y $75^{\circ}$ hacia el N-NE (entre 0 y $52^{\circ}$, fig. 3). Las observaciones de indicadores cinemáticos tales como porfiroclastos de plagioclasa y microclino asimétricos en las milonitas, señalan movimientos de carácter inverso, de tipo oblicuo compresivo desde el N-NE hacia el S-SO.

Por su parte, en la Faja TiPA las lineaciones de estiramiento mineral también poseen una dirección de inclinación preferentemente N-NE (entre 0 y $45^{\circ}$ ) con inmersión bastante elevada $\left(60-80^{\circ}\right)$ en el mismo sentido. El estudio de los indicadores cinemáticos indicaría que el sector dúctil presenta un carácter inverso, mientras que el sector frágil, presenta en general, una cinemática directa (López et al., 2006).

\section{Características geoquímicas}

Los análisis químicos se realizaron sobre roca total (tabla 1); algunas muestras se analizaron en el NEG-LABISE-UPF (Brasil), y otras en Actlabs (Canadá) y en las Universidades de Oviedo y Huelva (España). Los métodos utilizados varían según el laboratorio: el método utilizado en NEG-LABISEUPF es fluorescencia de rayos X (XRF) y las muestras se pulverizan para la determinación de elementos trazas ( $\mathrm{Ba}, \mathrm{Cr}, \mathrm{Nb}, \mathrm{Ni}, \mathrm{Rb}, \mathrm{Sr}, \mathrm{Y}$ y $\mathrm{Zr}$ ), mientras que para los elementos mayores se funden las muestras pulverizadas con metaborato/tetraborato de litio y se forma una perla.

En el laboratorio Actlabs (Canadá), se utiliza el método estandarizado «WRA+trace 4 Lithoresearch», que incluye fusión con metaborato/tetrabo- 
Tabla 1.-Análisis químicos de elementos mayores, menores (expresados en peso \%), trazas y Tierras Raras (expresados en ppm)

\begin{tabular}{|c|c|c|c|c|c|c|c|c|c|c|c|}
\hline & \multicolumn{6}{|c|}{ Granitos } & \multicolumn{5}{|c|}{ Rocas miloníticas } \\
\hline & 6958 & 6960 & 6792 & 6793 & 6798 & 6998 & 6790 & 6800 & 6806 & 6807 & 6804 \\
\hline $\mathrm{SiO}_{2}$ & 68,11 & 75,68 & 76,42 & 73,83 & 76,89 & 74,82 & 67,35 & 69,15 & 64,49 & 72,78 & 64,28 \\
\hline $\mathrm{TiO}_{2}$ & 0,36 & 0,13 & 0,19 & 0,36 & 0,12 & 0,20 & 0,61 & 0,46 & 0,64 & 0,32 & 0,55 \\
\hline $\mathrm{Al}_{2} \mathrm{O}_{3}$ & 15,90 & 13,09 & 12,98 & 13,03 & 12,91 & 13,44 & 15,27 & 15,14 & 17,37 & 14,23 & 16,26 \\
\hline $\mathrm{Fe}_{2} \mathrm{O}_{3} \mathrm{~T}$ & 3,77 & 1,21 & 1,25 & 3,24 & 0,98 & 1,77 & 4,60 & 4,06 & 4,34 & 2,56 & 5,92 \\
\hline $\mathrm{FeOt}$ & 3,40 & 1,09 & 1,13 & 2,92 & 0,88 & 1,60 & 4,14 & 3,66 & 3,91 & 2,31 & 5,33 \\
\hline $\mathrm{MgO}$ & 0,92 & 0,15 & 0,45 & 1,24 & 0,30 & 0,40 & 1,47 & 1,33 & 1,42 & 0,81 & 2,54 \\
\hline $\mathrm{MnO}$ & 0,05 & 0,04 & 0,05 & 0,06 & 0,05 & 0,05 & 0,07 & 0,10 & 0,11 & 0,06 & 0,14 \\
\hline $\mathrm{CaO}$ & 4,11 & 0,89 & 0,83 & 1,96 & 1,11 & 1,52 & 2,58 & 2,96 & 3,39 & 2,75 & 4,77 \\
\hline $\mathrm{Na}_{2} \mathrm{O}$ & 3,27 & 2,90 & 2,53 & 2,48 & 3,10 & 2,68 & 2,54 & 2,97 & 3,52 & 3,07 & 2,96 \\
\hline $\mathrm{K}_{2} \mathrm{O}$ & 2,33 & 4,67 & 4,68 & 3,77 & 4,53 & 5,25 & 3,72 & 3,06 & 3,85 & 2,96 & 1,83 \\
\hline $\mathrm{P}_{2} \mathrm{O}_{5}$ & 0,13 & 0,02 & 0,03 & 0,03 & 0,03 & 0,06 & 0,22 & 0,17 & 0,17 & 0,04 & 0,10 \\
\hline LOI & 0,51 & 0,78 & 1,02 & 0,88 & 0,70 & 0,58 & 1,32 & 1,04 & 0,95 & 0,52 & 1,01 \\
\hline Total & 99,45 & 99,57 & 100,42 & 100,88 & 100,72 & 100,78 & 99,75 & 100,44 & 100,24 & 100,10 & 100,36 \\
\hline $\mathrm{Cr}$ & 23 & 95 & 32 & 37 & $<10$ & 20 & $<10$ & 97 & 23 & $<10$ & 23 \\
\hline $\mathrm{Ni}$ & $<20$ & $<20$ & 34 & 43 & 32 & 8 & 12 & 25 & 33 & 33 & 32 \\
\hline $\mathrm{Rb}$ & 101 & 172 & 139 & 130 & 139 & 100 & 154 & 122 & 185 & 93 & 131 \\
\hline $\mathrm{Sr}$ & 145 & 59 & 93 & 159 & 100 & 69 & 146 & 142 & 230 & 396 & 190 \\
\hline $\mathrm{Y}$ & 9 & 28 & 40 & 24 & 32 & 6 & 40 & 25 & 41 & 22 & 35 \\
\hline $\mathrm{Zr}$ & 231 & 112 & 123 & 173 & 67 & 27 & 251 & 223 & 300 & 157 & 114 \\
\hline $\mathrm{Nb}$ & 8 & 9 & $<10$ & $<10$ & $<10$ & 6 & 19 & 14 & 15 & $<10$ & 15 \\
\hline $\mathrm{Ba}$ & 288 & 395 & 690 & 790 & 720 & 412 & n.d. & 491 & 908 & 557 & 205 \\
\hline $\mathrm{La}$ & 17,80 & 33,60 & & & & 22,67 & & & & & \\
\hline $\mathrm{Ce}$ & 36,10 & 72,30 & & & & 46,80 & & & & & \\
\hline $\operatorname{Pr}$ & 3,28 & 6,78 & & & & 5,72 & & & & & \\
\hline $\mathrm{Nd}$ & 13,20 & 28,70 & & & & 19,98 & & & & & \\
\hline $\mathrm{Sm}$ & 2,41 & 6,47 & & & & 3,36 & & & & & \\
\hline $\mathrm{Eu}$ & 1,00 & 0,76 & & & & 0,88 & & & & & \\
\hline $\mathrm{Gd}$ & 1,92 & 5,61 & & & & 2,55 & & & & & \\
\hline $\mathrm{Tb}$ & 0,31 & 0,97 & & & & 0,32 & & & & & \\
\hline Dy & 1,75 & 5,19 & & & & 1,50 & & & & & \\
\hline Ho & 0,35 & 1,03 & & & & 0,28 & & & & & \\
\hline $\mathrm{Er}$ & 1,07 & 3,37 & & & & 0,70 & & & & & \\
\hline $\mathrm{Tm}$ & 0,17 & 0,56 & & & & 0,11 & & & & & \\
\hline $\mathrm{Yb}$ & 1,04 & 3,53 & & & & 0,69 & & & & & \\
\hline $\mathrm{Lu}$ & 0,17 & 0,53 & & & & 0,11 & & & & & \\
\hline Hf & 6,40 & 4,30 & & & & n.d. & & & & & \\
\hline $\mathrm{Ta}$ & 1,65 & 2,07 & & & & 2,05 & & & & & \\
\hline Th & 6,64 & 18,00 & & & & 11,09 & & & & & \\
\hline
\end{tabular}

rato de litio, con determinaciones con XFR, INAA e ICP-MS.

En las muestras analizadas en España, los elementos mayores se determinaron por fluorescencia de rayos $\mathrm{X}$ (XRF) en la Universidad de Oviedo con un equipo marca Phillips PW2404. La precisión típica del método es superior al $\pm 1,5 \%$ relativo. Los elementos trazas fueron analizados en la Universidad de Huelva mediante plasma acoplado por inducción con espectrómetro de masas (ICP-MS) con un sistema HP-4500. La precisión y exactitud de la mayoría de los elementos se encuentra en el rango 5-10\%

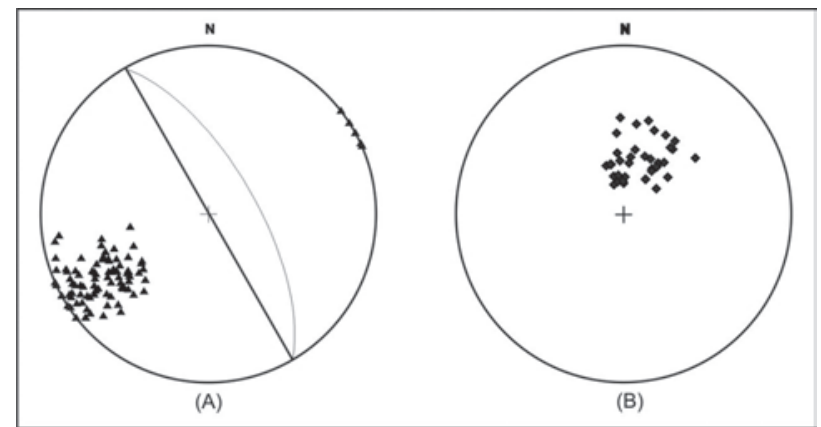

Fig. 3.-A) Foliación milonítica, y B) lineaciones de estiramiento mineral de las rocas de la Faja Milonítica Sur. 

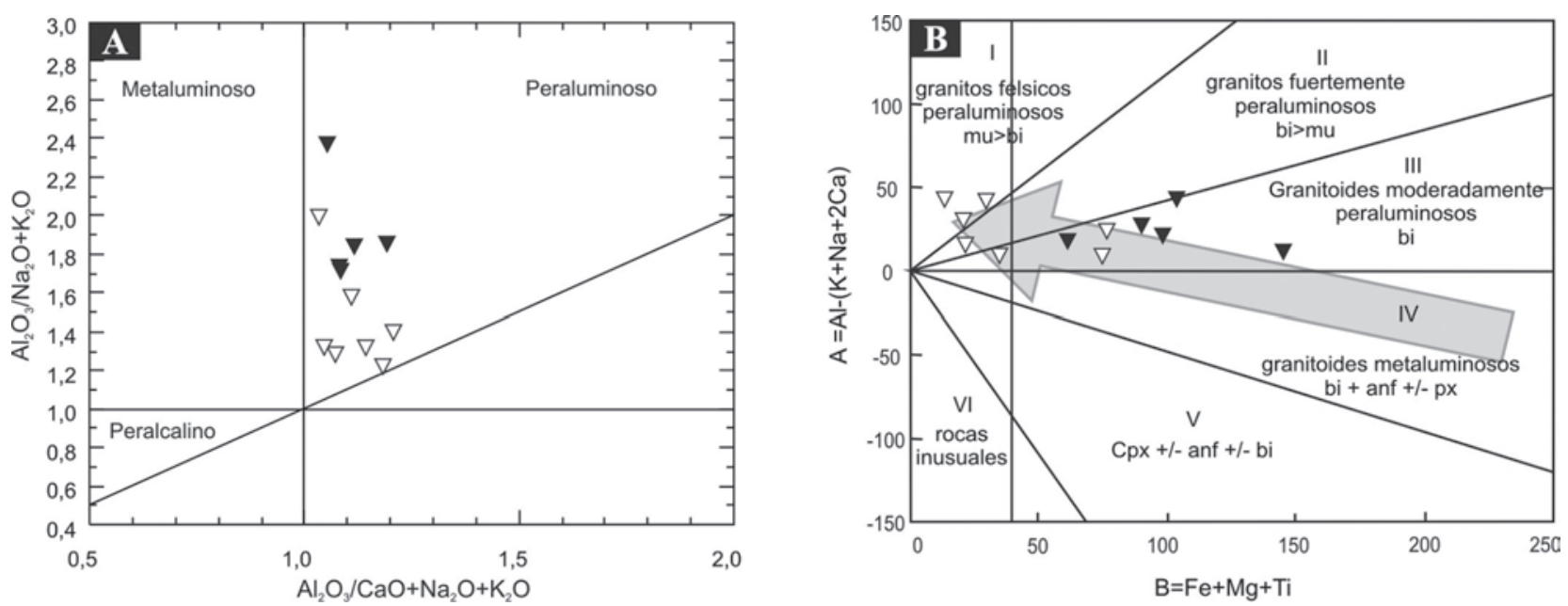

Fig. 4.-A) Diagrama de Maniar y Piccoli (1989) utilizando los índices de Shand; B) Diagrama de discriminación de Debon y Le Fort (1983). Símbolos: Plutón San Cristóbal (triángulos blancos), rocas miloníticas (triángulos negros), comentarios en el texto.

relativo, y fueron controlados por análisis repetidos de los estándares internacionales SARM-1 (granito) y SARM-4 (norita). Detalles metodológicos se encuentran en De la Rosa et al. (2001).

Los granitos del plutón San Cristóbal y las rocas miloníticas poseen características de típicos granitos calcoalcalinos (por ej., Lee et al., 2007), con tenores de $\mathrm{SiO}_{2}$ entre 67 y $76 \%$. Son débil a moderadamente peraluminosas, con un índice de saturación en alúmina (ASI) entre 1,03 y 1,20 (fig. 4A); debe tenerse en cuenta que las rocas miloníticas probablemente sufrieron movilización de ciertos elementos como los álcalis, por lo que el índice ASI no correspondería al original del protolito. En el diagrama A-B de Debon \& Le Fort (1983, fig. 4B) las rocas se proyectan en el campo de los granitoides moderadamente peraluminosos y en la parte inferior del campo de granitos félsicos peraluminosos, donde característicamente se concentran las rocas débilmente peraluminosas formadas a partir de rocas metaígneas básicas (Villaseca et al., 1998). La flecha en la figura 4B indica la tendencia metaluminosa a débilmente peraluminosa de las rocas máficas y los granitoides de plutón Palanche.

En los diagramas de variación de Harker de óxidos vs. $\mathrm{SiO}_{2}$ (fig. 5), se observan buenos coeficientes de correlación tanto positivos como negativos.

Los tenores de $\mathrm{FeOt}, \mathrm{MgO}, \mathrm{Al}_{2} \mathrm{O}_{3}, \mathrm{TiO}_{2}, \mathrm{CaO}$ y $\mathrm{MnO}$ muestran una clara correlación negativa con el aumento de la $\mathrm{SiO}_{2}$. Con respecto a los álcalis se puede ver que el $\mathrm{K}_{2} \mathrm{O}$ presenta una correlación positiva, aunque con mayor dispersión que el resto de los óxidos, mientras que el $\mathrm{Na}_{2} \mathrm{O}$ tiene una ligera correlación negativa.

Por otra parte, en el diagrama logarítmico $\mathrm{Rb} v s$. $\mathrm{Y}+\mathrm{Nb}$ (Pearce et al., 1984, fig. 6A) las muestras se proyectan en el campo de arco magmático (VAG). También se ha representado el contenido promedio de los elementos trazas incompatibles y $\mathrm{K}_{2} \mathrm{O}$ en los granitos del plutón San Cristóbal, normalizados a ORG (granito de dorsal oceánica) de Pearce et al. (1984, fig. 6B). En la misma gráfica se han agregado las tendencias de típicos granitos de arco magmático, de intraplaca y sincolisionales según estos autores. Se puede ver que las rocas estudiadas muestran notable afinidad con los granitos de arco magmático, con un pequeño empobrecimiento en $\mathrm{Th}, \mathrm{Nb}, \mathrm{Ce}, \mathrm{Zr}, \mathrm{Sm}, \mathrm{Y}$ e $\mathrm{Yb}$ con respecto a éstos. Asimismo puede verse una clara distinción con los granitos de intraplaca, mientras que con respecto a los sincolisionales, las rocas estudiadas se encuentran más empobrecidas en $\mathrm{Rb}$ y más enriquecidas en $\mathrm{Hf}, \mathrm{Zr}$, Y y Yb.

Las rocas graníticas del plutón San Cristóbal presentan patrones de elementos de trazas muy similares a las granodioritas y tonalitas del plutón Palanche. Esto puede verse en la figura 7 que corresponde a diagramas spider normalizados a un MORB tipo normal y a condrito (Sun \& McDonough, 1989). Se puede ver claramente que ambos plutones muestran un patrón similar aunque el Plutón San Cristóbal se encuentra algo más empobrecido en elementos trazas que el plutón Palanche con respecto al MORB, principalmente en $\mathrm{Sr}, \mathrm{Nd}, \mathrm{Zr}$, Hf, Y, $\mathrm{Yb}$ y $\mathrm{Lu}$, mientras que con respecto al condrito, 

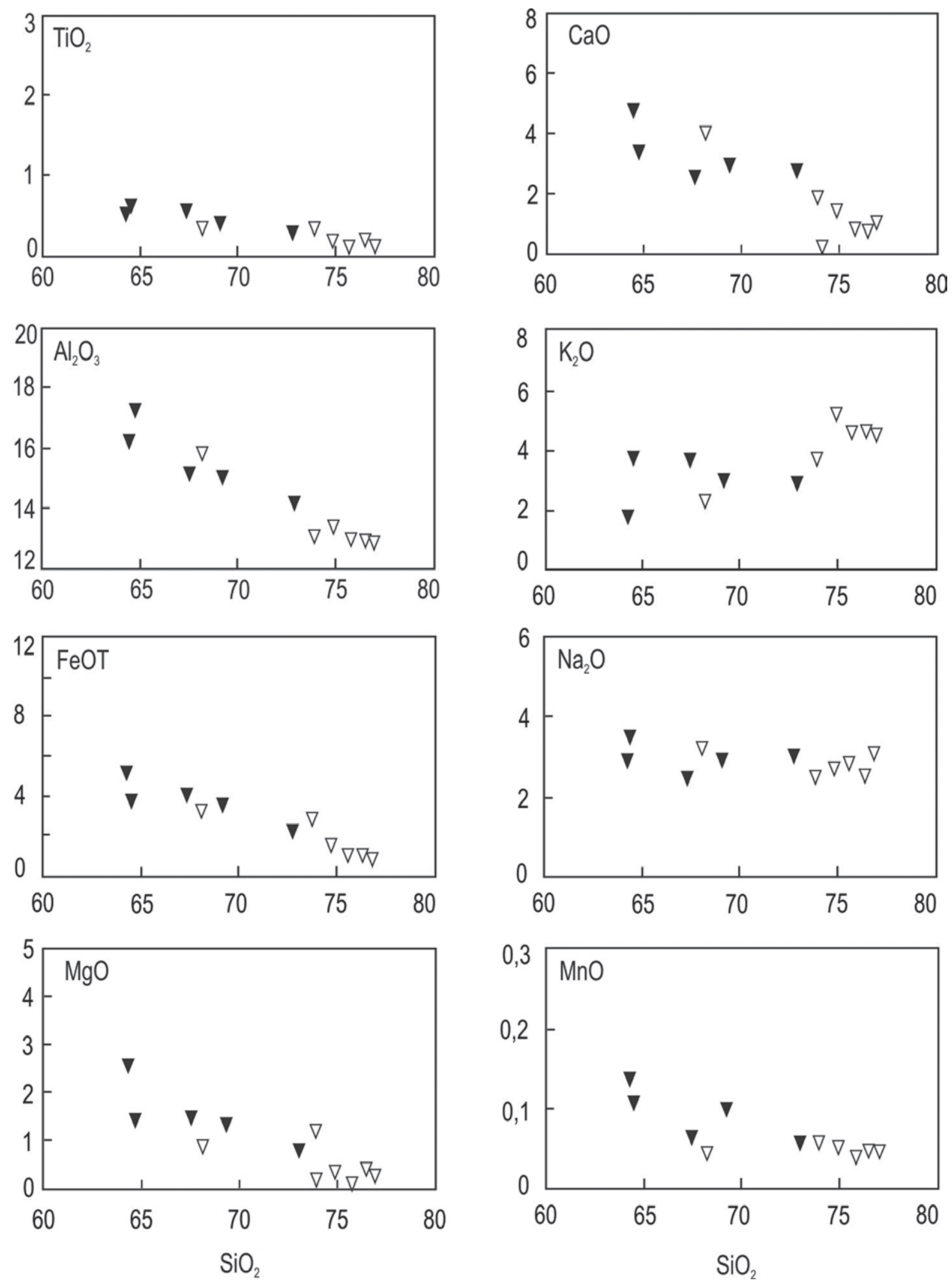

Fig. 5.-Diagramas Harker de óxidos vs. $\mathrm{SiO}_{2}$. Símbolos: Plutón San Cristóbal (triángulos blancos), rocas miloníticas (triángulos negros). 

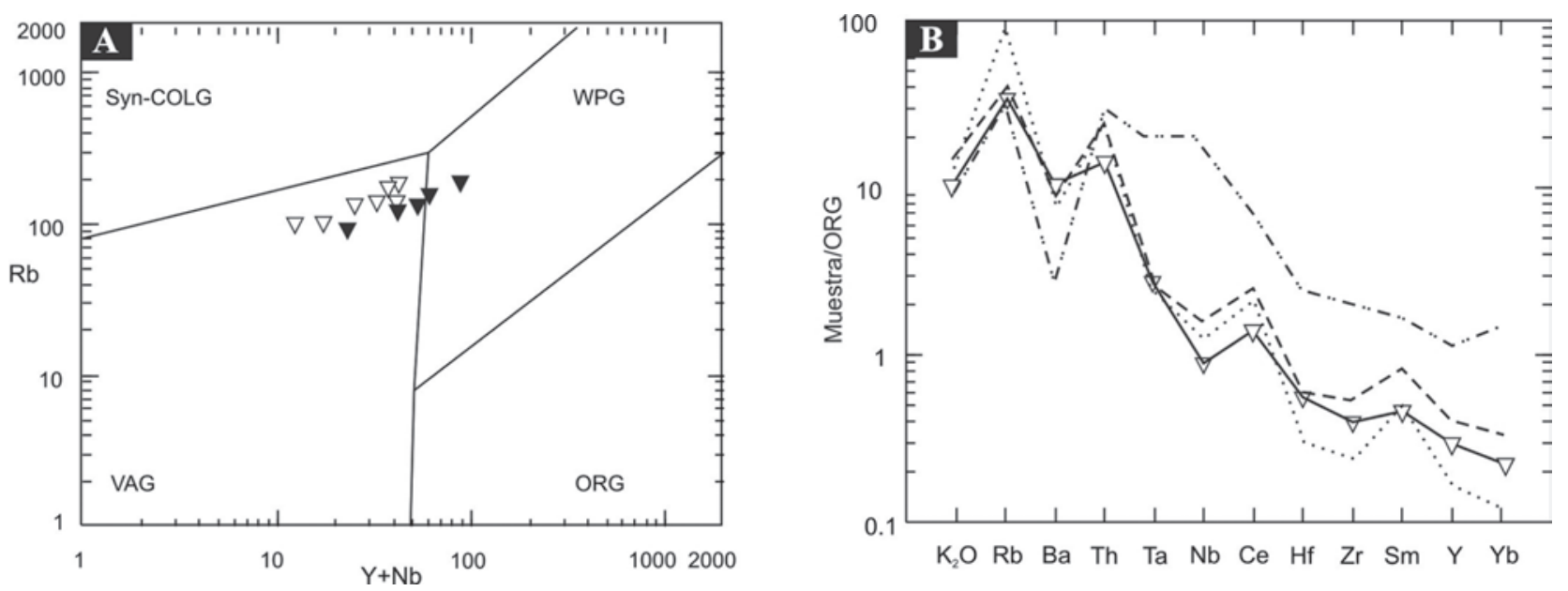

Fig. 6.-A) Diagrama de discriminación tectónica de Pearce et al. (1984); B) Diagrama de elementos trazas y $\mathrm{K}_{2} \mathrm{O}$ normalizados a un ORG (Pearce et al., 1984). Símbolos: Plutón San Cristóbal (triángulos blancos), rocas miloníticas (triángulos negros), granitos de intraplaca (rayas y puntos), granitos de arco magmático (rayas), granitos sincolisionales (puntos), comentarios en el texto.
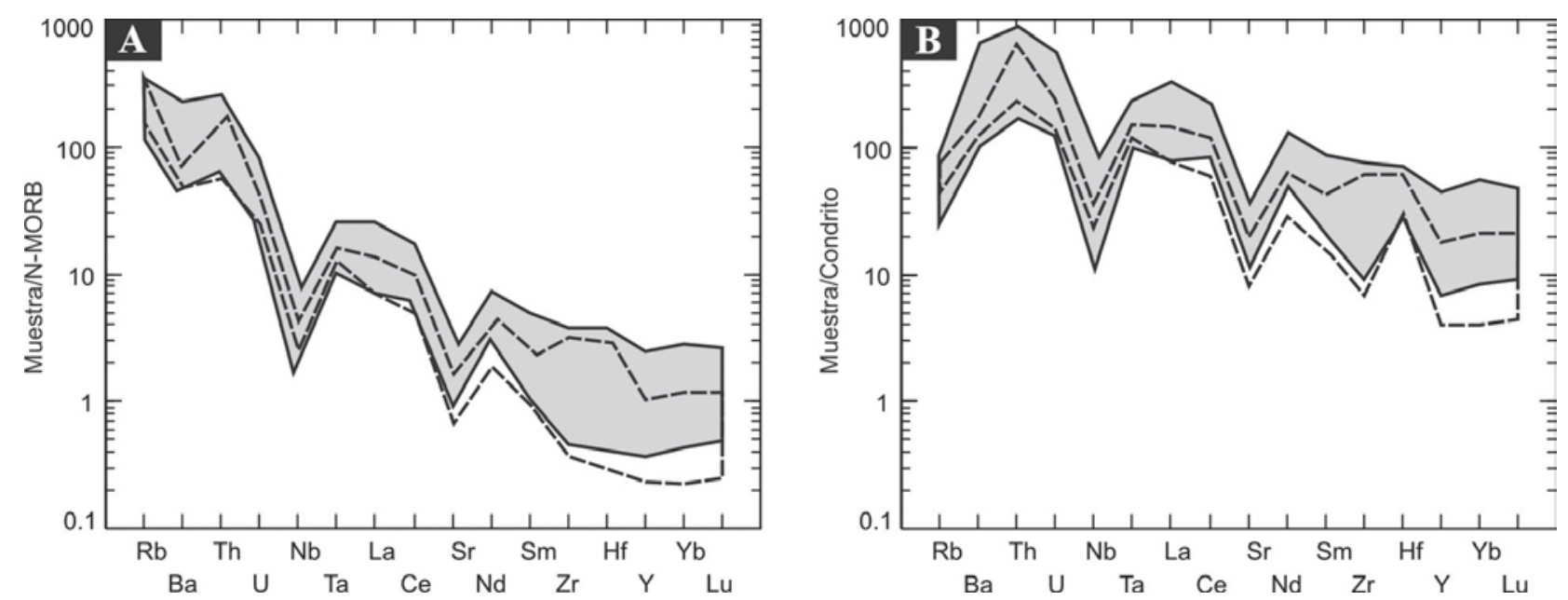

Fig. 7.-A) Diagrama spider normalizado a un MORB tipo normal (Sun and McDonough, 1989); B) Diagrama spider normalizado a condrito (Sun and McDonough, 1989). Área sombreada: plutón Palanche, área en blanco: plutón San Cristóbal.

muestra un menor contenido en $\mathrm{Y}, \mathrm{Yb}$ y Lu que el plutón Palanche. Así, los granitos del plutón San Cristóbal muestran la misma signatura geoquímica que las granodioritas y tonalitas del plutón Palanche, lo que indicaría, sumado a otras evidencias petrográficas y geoquímicas, una relación genética entre ambos (Bellos, 2008).

\section{Interpretación y Conclusiones}

El plutón San Cristóbal está constituido por granitos calcoalcalinos, débil a moderadamente peraluminosos. Su mineralogía y composición química sugieren una relación genética con el plutón Palanche, de características geoquímicas metaluminosas.

Ambos plutones corresponden a granitos de tipoI y muestran afinidad con los granitoides metaluminosos dominantes en el Sistema de Famatina y en el Batolito Ulapes-Los Llanos (Pankhurst et al., 1998; Dahlquist et al., 2005; Saal, 1993; Saal et al., 1996; Toselli et al., 1988; Saavedra et al., 1992, 1996, 1998) y se diferencian de los granitoides fuertemente peraluminosos de las Sierras Pampeanas (Rapela et al., 1996; López et al., 1996; Rossi et al., 2002).

La asociación paragenética de las corneanas (facies esquistos verdes) indicaría que el metamorfismo ocurrió a temperaturas mayores a $640{ }^{\circ} \mathrm{C}$ y 
presiones inferiores a los $5 \mathrm{Kbar}$, lo cual acota la profundidad de emplazamiento del plutón San Cristóbal a un máximo de $12 \mathrm{~km}$.

En base a las características texturales y la mineralogía de las milonitas de la Faja Milonítica Sur (cuarzo + feldespato potásico + plagioclasa + biotita), la deformación habría ocurrido en una zona cercana a la transición frágil-dúctil (Sibson, 1977, Simpson et al., 2003), en condiciones de facies esquistos verdes (Bellos, 2005b, 2008). Esto apoyaría la idea de que la profundidad mínima de emplazamiento de los granitos es de alrededor de $12 \mathrm{~km}$, si es que éstos se deformaron en el lugar de emplazamiento. Alternativamente, si los granitos se emplazaron en niveles más profundos, la deformación habría tenido lugar durante el ascenso en la corteza hacia su exhumación.

Del análisis cinemático se interpreta que el movimiento cizallante habría sido de carácter inverso de tipo oblicuo compresivo desde el N-NE hacia el S-SO.

Hasta el momento se carece de edades absolutas confiables de estos granitoides. Sin embargo, una errorcrona $\mathrm{Rb} / \mathrm{Sr}$ sobre roca total arroja una edad de 488 Ma para el plutón Palanche (Bellos, 2008). Esta edad es consistente con las edades U-Pb sobre circones obtenidas para los granitoides tipo-I de la sierras de Famatina y Chepes (entre 478 y $490 \mathrm{Ma}$ ) por Pankhurst et al. (2000) y Dahlquist et al. (2005). Posiblemente el plutón San Cristóbal tenga una edad similar.

Así, los granitos estudiados se habrían emplazado en un ambiente de arco magmático continental (por ej., el Arco Famatiniano), desarrollado en el borde occidental de Gondwana durante el Paleozoico Inferior.

Con respecto a la edad del evento deformativo asociado a la Faja Milonítica Sur, posiblemente sea contemporáneo al evento metamórfico que deformó a las rocas de la Faja Milonítica TiPA, en el noroeste de la sierra (López \& Toselli, 1993). Diversos autores dataron por diferentes métodos estas rocas obteniendo edades que abarcan el Devónico Inferior, desde 436 a 402 Ma (López et al., 2000; Höckenreiner et al., 2001, 2003). Es posible que la deformación en el sur de la Sierra de Velasco, también sea de la misma edad.

\section{AGRADECIMIENTOS}

Este trabajo fue realizado gracias a la financiación de los Proyectos CIUNT 26/G321 y 26/G439. Asimismo se agradece al CONICET, al NEG-LABISE-UPF y a las Universidades de Oviedo y Huelva. Los autores agradecen especialmente a los revisores, Dres. Carlos Villaseca y Lucio Pinotti, por las valiosas sugerencias realizadas que contribuyeron a mejorar este trabajo.

\section{Referencias}

Báez, M.A. (2006). Geología, petrología y geoquímica del basamento ígneo metamórfico del sector norte de la Sierra de Velasco, provincia de La Rioja. Tesis Doctoral, Universidad Nacional de Córdoba, 207 pp.

Báez, M.A. \& Basei, M. (2005). El plutón San Blas, magmatismo postdeformacional carbonífero en la Sierra de Velasco, La Rioja, Argentina. En: Simposio Bodenbender: Trabajos completos. Serie de Correlación Geológica (Aceñolaza, F.G.; Hünicken, M.; Toselli, A.J. \& Aceñolaza, G.F., eds.) 19: 239-246.

Báez, M.A.; Basei, M.; Toselli, A. \& Rossi de Toselli, J.N. (2004). Geocronología de granitos de la Sierra de Velasco (Argentina): Reinterpretación de la secuencia magmática. Simpósio 40 anos de geocronologia no Brasil. São Paulo, Brasil. Resumos: 85.

Bellos, L.I. (2000). Contribución al Conocimiento Geológico de Granitoides y Rocas Asociadas de un Sector del Flanco Sur-Occidental de la Sierra de Velasco, La Rioja, Argentina. Trabajo de Seminario Final, Facultad de Ciencias Naturales e IML, Universidad Nacional Tucumán, 90 pp.

Bellos, L.I. (2005a). Geología y petrología del sector austral de la Sierra de Velasco, al sur de los $29^{\circ} 44^{\prime} \mathrm{S}$, La Rioja, Argentina. En: Simposio Bodenbender: Trabajos completos. Serie de Correlación Geológica (Aceñolaza, F.G.; Hünicken, M.; Toselli, A.J. \& Aceñolaza, G.F., eds.) 19: 261-278.

Bellos, L.I. (2005b). Estructura y petrografía de las rocas miloníticas y cataclásticas del sector sur de la Sierra de Velasco, La Rioja, Argentina. XVI Congreso Geológico Argentino. La Plata, Bs. As. Actas IV: 665-672.

Bellos, L.I.; Grosse, P.; Ruiz, A.; Rossi, J.N. \& Toselli, A.J. (2002). Petrografía y geoquímica de granitoides del flanco sud-occidental de la Sierra de Velasco, La Rioja, Argentina. XV Congreso Geológico Argentino. El Calafate. Actas 2: 81-86.

Bellos, L.I. (2008). Petrología de los granitoides del sur de la Sierra de Velasco y su significación regional. Tesis Doctoral, Facultad de Ciencias Exactas, Físicas y Naturales, Universidad Nacional de Córdoba, 334 pp.

Bucher, K. \& Frey, M. (1994). Petrogenesis of metamorphic rocks. Springer-Verlag, Berlín, Alemania, $318 \mathrm{pp}$.

Dahlquist, J.A.; Pankhurst, R.J.; Rapela, C.W.; Casquet, C.; Fanning, M.C.; Alasino, P. \& Báez, M.A. (2006). The San Blas Pluton: An Example of the Carboniferous Plutonism in The Sierras Pampeanas, Argentina. Journal of South American Earth Sciences. 20: 341-350. doi:10.1016/j.jsames.2005.08.006

Dahlquist, J.A.; Rapela, C.W.; Pankhurst, R.J.; Baldo, E.G.; Saavedra, J. \& Alasino, P.H. (2005). Los granitoides de la Sierra de Chepes y su comparación con granitoides paleozoicos de las Sierras Pampeanas: implicancias para el orógeno famatiniano. Revista de la Asociación Geológica Argentina, serie D: publicación especial, 8: 87-108.

Debon, F. \& Le Fort, P. (1983). A chemical-mineralogical classification of common plutonic rocks and asso- 
ciations. Transaction of the Royal Society of Edinburgh: Earth Sciences, 73: 135-149.

De la Rosa, J. D.; Chacón, H.; Sánchez de la Campa, A.; Carrasco, R. \& Nieto, J.M. (2001). Metodología y análisis de elementos trazas-REE mediante ICP-MS del standard SARM 1 granito y SARM 4 norita. III Congreso Ibérico de Geoquímica, Zaragoza, España. Actas: 435-438.

Escuder Viruete, J.; Carbonell, R.; Martí, D. \& PérezEstaún, A. (2001). Interacción fluido-roca a lo largo de las superficies de fractura: efectos mineralógicos y texturales de las alteraciones observadas en el Plutón Granítico de Albalá, SO del Macizo Hercínico Ibérico. Boletín Geológico y Minero, 112 (3): 59-78.

Grosse, P. (2000). Geología y petrología del sector comprendido entre el Bolsón de Paluqui y la Quebrada del Tigre, en el flanco Sur-Occidental de la Sierra de Velasco, Provincia de La Rioja. Trabajo de Seminario Final. Facultad de Ciencias Naturales e Instituto M. Lillo, Universidad Nacional de Tucumán, 111 pp.

Grosse, P.; Bellos, L.I.; Báez, M.A.; Rossi de Toselli, J.N. \& Toselli, A.J. (2003). Ordovician Magmatism of the Sierra de Velasco, La Rioja, Argentina. In: Ordovician from the Andes. INSUGEO, Serie de Correlacion Geológica (Albanesi, G.L.; Beresi, M.S \& Peralta, S.H., eds.) 17: 223-226.

Grosse, P. \& Sardi, F. (2005). Geología de los Granitos Huaco y Sanagasta, Sierra de Velasco, La Rioja. En: Simposio Bodenbender: Trabajos completos. Serie de Correlación Geológica (Aceñolaza, F.G.; Hünicken, M.; Toselli, A.J. \& Aceñolaza, G.F., eds.) 19: 221-238.

Grosse, P.; Söllner, F.; Báez, M.A.; Toselli, A.J.; Rossi, J.N. \& de la Rosa, J.D. (2009). Lower Carboniferous post-orogenic granites in central-eastern Sierra de Velasco, Sierras Pampeanas, Argentina: U-Pb monazite geochronology, geochemistry and $\mathrm{Sr}-\mathrm{Nd}$ isotopes. International Journal of Earth Sciences, 98: 1001-1025. doi:10.1007/s00531-007-0297-5

Höckenreiner, M.; Söllner, F. \& Miller, H. (2001). The TIPA shear zone (NW Argentina): evidence of Early Devonian movement verified by $\mathrm{Sm}-\mathrm{Nd}$ dating garnet and whole rock systems. III Simposio Sudamericano de Geología Isotópica Pucón, Chile. Art. 474, 3 pp.

Höckenreiner, M.; Söllner, F. \& Miller, H. (2003). Dating the TIPA shear zone: an Early Devonian terrane boundary between the Famatinian and Pampean systems (NW-Argentina). Journal of South American Earth Sciences, 16: 45-66.

doi:10.1016/S0895-9811(03)00018-X

Lee, C.-T.A.; Morton, D.M.; Kistler, R.W. \& Baird, A.K. (2007). Petrology and tectonics of phanerozoic continent formation: From island arcs to accretion and continental arc magmatism. Earth and Planetary Science Letters, 263: 370-387. doi:10.1016/j.eps1.2007.09.025

López, J.P. (1998). Petrología, geoquímica y geología estructural de la Sierra de Copacabana (provincia de Catamarca, República Argentina) y su significado geotectónico en el contexto del margen occidental de Gondwana. Estudios Geológicos, 54: 109-122. doi:10.3989/egeol.98543-4210
López, J.P. (2005). Evidencias de dos eventos deformacionales en el flanco noroeste de la sierra de Velasco, La Rioja, Argentina. Revista de la Asociación Geológica Argentina, serie D: publicación especial, 8: 149-154.

López, J.P.; Bellos, L.I. \& Grosse, P. (2006). Estructura y petrografía de zonas de cizalla en la Sierra de Velasco, La Rioja. XII Reunión sobre microtectónica y geología estructural. Revista Asociación Geológica Argentina, serie D: publicación especial, 9: 201-206.

López, J.P.; Durand, F.R. \& Toselli, A.J. (1996). Zonas de Cizalla en el Flanco Noroccidental de la Sierra de Velasco, La Rioja, Argentina. XIII Congreso Geológico Argentino y III Congreso de Exploración de Hidrocarburos. Buenos Aires. Actas II: 179-185.

López, J.P.; Grosse, P. \& Toselli, A.J. (2007). Faja de Deformación La Horqueta, sierra de Velasco, Sierras Pampeanas, NO de Argentina: petrografía, geoquímica, estructuras y significado tectónico. Estudios Geológicos, 63:5-18. doi:10.3989/egeol.07632197

López, J.P.; Sales de López, A. \& Stipp Basei, M. (2000). Nueva edad K/Ar en la historia evolutiva de la Faja Milonítica TIPA, en el Noroeste Argentino. Zentralblatt für Geologie und Paläontologie. Stuttgart. Alemania. Teil I: Heft 7/8, 895-902.

López, J.P., \& Toselli, A.J., (1993). La faja milonítica TIPA: faldeo oriental del Sistema de Famatina, Argentina. XII Congreso Geológico Argentino, Mendoza, Argentina. Actas, 3: 39-42.

Maniar, P.D. \& Piccoli, P.M. (1989). Tectonic discrimination of granitoids. Geological Society of America. Bulletin, 101: 635-643. doi:10.1130/00167606(1989)101<0635:TDOG>2.3.CO;2

Pankhurst, R.J.; Rapela, C.W. \& Fanning, C. (2000). Age and origin of coeval TTG, I- and S- type granites in the Famatinian Belt of NW Argentina. Transactions of the Royal Society of Edinburgh. Earth Sciences, 91: 151-168.

Pankhurst, R.J.; Rapela, C.W; Saavedra, J.; Baldo, E.; Dahlquist, J.A.; Pascua, I. \& Fanning, C. M. (1998). The Famatinian magmatic arc in the central Sierras Pampeanas: an Early to Mid-Ordovician continental arc on the Gondwana margin. In: The Proto-Andean Margin of Gondwana (Pankhurst, R.J. \& Rapela, C.W., eds.). Geological Society of London, Special Publications, 142: 343-367.

Paschier, C.W. \& Trouw, R.A.J. (1996). Microtectonics. Springer-Verlag Berlin Heidelberg. Alemania. 289 pp.

Pearce, J.A.; Harris, N.B.W. \& Tindle, A.G. (1984). Trace element discrimination diagrams for the tectonic interpretation of granite rocks. Journal of Petrology, 25: 956-983.

Pérez, W.; Lencina, R. \& Durand, F. (1991). Las milonitas de la Sierra de Paimán, La Rioja, Argentina: indicadores cinemáticas, edad y significado geotectónico. $6^{\circ}$ Congreso Geológico Chileno, I: 6-10.

Rapela, C.W.; Pankhurst, R.J.; Baldo, E.; Casquet, C.; Galindo,C.; Fanning, C.M. \& Saavedra, J. (2001). Ordovician metamophism in the Sierras Pampeanas: New U-Pb SHRIMP ages in Central-East Valle Fértil and the Velasco Batholith. Third South American Sym- 
posium on Isotope Geology (III SSAGI). Pucón, Chile. Artículo 616: 1-4. En CD-ROM.

Rapela, C.W.; Saavedra, J.; Toselli, A.J. \& Pellitero, E. (1996). Eventos magmáticos fuertemente peraluminosos en las Sierras Pampeanas. XIII Congreso Geológico Argentino y III Congreso de Exploración de Hidrocarburos. Buenos Aires. Acta V: 337-353.

Rossi, J.N. \& Toselli, A.J. (2004). Termobarometría de las corneanas granatíferas del flanco sudoccidental de la Sierra de Velasco. La Rioja, Argentina. $7^{\circ}$ Congreso de Mineralogía y Metalogenia. Río Cuarto. Córdoba. 403-408.

Rossi, J.N.; Toselli, A.J.; Saavedra, J.; Sial, A.N.; Pellitero, E. \& Ferreira, V.P. (2002). Common crustal sources for contrasting peraluminous facies in the Early Paleozoic Capillitas Batholith, NW Argentina. Gondwana Research, 5-2: 325-337.

Saal, A.E. (1993). El basamento Cristalino de la Sierra de Paganzo, provincia de La Rioja. Tesis Doctoral, Facultad de Ciencias Exactas, Físicas y Naturales, Universidad Nacional de Córdoba. Vol. I, 206 pp.

Saal, A.E.; Toselli, A.J. \& Rossi de Toselli, J.N. (1996). Granitoides y rocas básicas de la Sierra de Paganzo. En: Geología del Sistema de Famatina (Aceñolaza, F.G.; Millar, H. \& Toselli, A.J., eds) Münchner Geologische Hefte, 19 (Rehihe A): 199-209.

Saavedra, J.; Pellitero, E.; Rossi, J. \& Toselli, A. (1992). Magmatic evolution of the $\mathrm{C}^{\mathrm{o}}$ Toro granite, a complex ordovician pluton of northwestern Argentina. Journal of South American Earth Sciences, 5: 21-32. doi:10.1016/0895-9811(92)90057-6

Saavedra, J.; Toselli, A.J.; Rossi de Toselli, J.N. \& Pellitero, E. (1996). Granitoides y rocas básicas del Cerro Toro. In: Geología de Sistema de Famatina (Aceñolaza, F.G.; Miller, H \& Toselli, A.J., eds.). Münchner Geologische Hefte, 19 (Rehihe A): 229-240.

Saavedra, J.; Toselli, A.J.; Rossi de Toselli, J.N.; Pellitero, E. \& Durand, F. (1998). The Early Paleozoic magmatic record of the Famatinian System: a review. In: The Proto-Andean Margin of Gondwana (Pankhurst, R.J. \& Rapela, C.W., eds.). Geological Society of London, Special Publications, 142: 283-295.
Sibson, C. (1977). Fault rocks and fault mechanisms. Journal of the Geological Society of London, 133: 191-214. doi: 10.1144/gsjgs.133.3.0191

Simpson, C.; Law, R.; Gromet, L.P.; Miro, R. \& Northrup, C. (2003). Paleozoic deformation in the Sierras de Córdoba and Sierra de Las Minas, eastern Sierras Pampeanas, Argentina. Journal of South American Earth Sciences 15: 749-764. doi:10.1016/S0895-9811(02)00130-X

Sun, S.S. \& McDonough, W.F. (1989). Chemical and isotopic systematic of oceanic basalts: implications for mantle composition and processes. In: Magmatism in ocean basins (Saunders, A.D. \& Norry, M.J., eds.). Geological Society of London, Special Publication 42: 313-345.

Toselli, A.J.; Aceñolaza, F.G. \& Rossi de Toselli, J.N. (1986). A Proposal for the Systematization of the Upper Precambrian - Lower Paleozoic Basement in the Sierras Pampeanas, Argentina. Zentral Blatt fur Geologie und Palaontologie, Stuttgart. Alemania. Teil I. Heft 9/10: 1227-1233.

Toselli, A.; Rossi, J.; Saavedra, J.; Pellitero, E. \& Medina, M.E. (1988). Aspectos petrológicos y geoquímicos de los granitoides del entorno de Villa Castelli, Sierras Pampeanas Occidentales-Sistema de Famatina, Argentina. 5 Congreso Geológico Chileno, Antofagasta, Actas III: 117-128.

Toselli, A.J.; Miller, H.; Aceñolaza, F.G.; Rossi, J.N. \& Söllner, F. (2007). The Sierra de Velasco (northwestern Argentina) - An example of polyphase magmatism at the margin of Gondwana. Neus Jarhbuch für Geologisch und Paläontologisch Abhandlunger, 246: 325-345. doi:10.1127/0077-7749/2007/0246-0325

Villaseca, C.; Barbero, L. \& Herreros V. (1998). A reexamination of the typology of peraluminous granite types in intracontinental orogenic belts. Transactions of the Royal Society of Edinburgh: Earth Sciences, 89: 113-119.

Recibido el 17 de junio de 2009 Aceptado el 30 de octubre de 2009 Publicado online el 2 de marzo de 2010 
